\title{
Interpreting DNAPL Saturations in a Laboratory-Scale Injection with GPR Data and Direct Core Measurements
}

\section{Open-File Report 03-349}

By Raymond H. Johnson ${ }^{1}$ and Eileen P. Poeter ${ }^{2}$

${ }^{1}$ United States Geologic Survey, Denver, CO

${ }^{2}$ Colorado School of Mines, Golden, CO

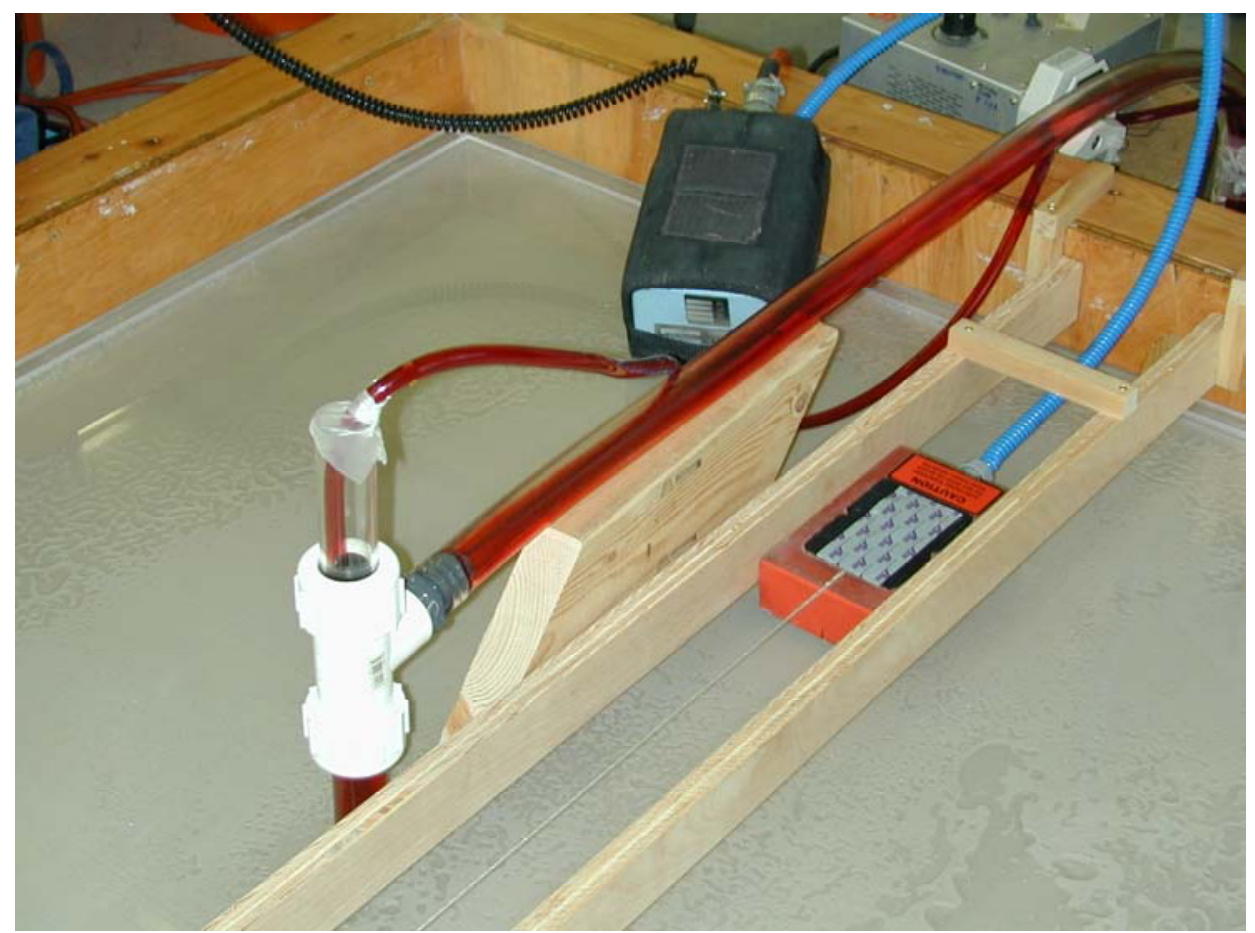

This report is preliminary and has not been reviewed for conformity with U.S. Geological Survey editorial standards or with the North American Stratigraphic Code.

Any use of trade, firm, or product names is for descriptive purposes only and does not imply endorsement by the U.S. Government.

U.S. Department of the Interior

U.S. Geological Survey 


\begin{abstract}
Ground penetrating radar (GPR) is used to track a dense non-aqueous phase liquid (DNAPL) injection in a laboratory sand tank. Before data reduction, GPR data provide a qualitative measure of DNAPL saturation and movement. One-dimensional (1D) GPR modeling provides a quantitative interpretation of DNAPL volume within a given thickness during and after the injection. This is confirmed qualitatively by visual inspection of cores and two-dimensional GPR modeling. DNAPL saturation in sublayers of that thickness could not be quantified because calibration of the 1D GPR model is non-unique when both permittivity and depth of multiple layers are unknown. Accurate quantitative interpretation of DNAPL volumes using 1D GPR modeling requires: 1) identification of a suitable target that produces a strong reflection and is not subject to any multidimensional interference; 2) knowledge of the exact depth of that target; and 3) use of two-way radar-wave travel times through the medium to the target to determine the permittivity of the intervening material, which eliminates reliance upon reflection amplitude. With geologic conditions that are suitable for GPR surveys (i.e., shallow depths and low electrical conductivities), the procedures in this laboratory study can be adapted to a field site to identify DNAPL source zones after a release has occurred.
\end{abstract}

\title{
Introduction
}

The identification of dense non-aqueous phase liquids (DNAPLs) in the subsurface is the first step toward remediation of an area affected by dense organic contaminants. Since DNAPLs are the source zone for dissolved constituents, the removal or isolation of the pure phase DNAPL is a priority for successful remediation. Identification of DNAPL source zones has traditionally relied upon the use of soil cores and monitoring wells. Analyses of soil cores can provide quantitative values for DNAPL saturation with depth. Monitoring wells can provide direct evidence of DNAPL due to the accumulation of free product, but do not provide the distribution of DNAPL saturations with depth. Both require a large expense, and drilling risks the remobilization of residual DNAPL zones. Dissolved concentrations of organic contaminants in monitoring wells outside of the source zone provide indirect evidence of possible DNAPL source zone locations.

Surface geophysical methods are an attractive alternative for the detection of DNAPL source zones because they are non-intrusive and time effective. Qualitative information is readily acquired, but acquisition of quantitative DNAPL saturations requires detailed analysis of the geophysical data and favorable geologic conditions. A variety of geophysical methods were used at the Canadian Forces Base Borden in a 9 m by $9 \mathrm{~m}$ controlled field cell where perchloroethylene (PCE) was intentionally injected and monitored (Brewster and others, 1995; Greenhouse and others, 1993). The ground 
penetrating radar data (GPR) from this PCE injection was analyzed to determine the distribution of DNAPL saturations (Sneddon and others, 2002) and used to calibrate a multiphase flow simulation (Johnson and Poeter, 2003a). The calibration statistics from Johnson and Poeter (2003a) led to the conclusion that the interpretation of the GPR data may be biased, especially in a channel where focusing of the GPR rays could lead to an overestimation of DNAPL saturation. However, it was not possible to determine whether the biased residuals resulted from error in the GPR interpretation or inaccuracies in the multiphase flow model.

The research presented here was designed to study the accuracy of DNAPL saturations interpreted from GPR data. GPR data were collected in a small sand tank during an injection of a non-toxic DNAPL. The GPR data were analyzed before, during, and after the injection to confirm the known geologic arrangement and quantify DNAPL saturations. Cores were taken post-injection, cut in sections and weighed to independently determine DNAPL saturations.

\section{Tank Design and Data Collection}

A sand tank was created by lining a plastic container with clay to create the desired geometry (Figures 1 and 2). Angled clay walls were used to evaluate the affect of a channel in two-dimensions and a bowl in three-dimensions on the GPR response. A steel rod was placed in the tank and a steel sheet was placed below the tank to provide known targets for the GPR interpretation. The tank was filled with tap water that was de-gassed by boiling and \#45 Ottawa silica sand from the U. S. Silica Company was sifted manually into the tank. Deposition of the sand through the water created layers of slightly varying sand sizes because the sand grains separated as they fell through the water column (Figure 3). Coarse sand lenses on the order of 0.5 to 1.0 centimeters $(\mathrm{cm})$ thick were flat to slightly sloped (darker color in Figure 3) with thin intervening layers of fine sand on the order of 0.1 to $0.3 \mathrm{~cm}$ thick (lighter color).

The tank geometry included $2.54 \mathrm{~cm}$ of water-saturated sand below the bottom of the clay to allow for coring and a $1.27 \mathrm{~cm}$ thick Plexiglas sheet that covered the tank (Figures 1 and 2). The Plexiglas sheet was used to create a dry, smooth surface for the GPR antenna. Two outlet ports $(2.54 \mathrm{~cm}$ in diameter) were installed at the top of the sand, one in the northeast corner of the tank and one in the southwest corner of the tank to allow water to flow out of the tank as the DNAPL was injected. As discussed later, GPR data indicated that the upper $3.81 \mathrm{~cm}$ of sand was not fully saturated. The precise thickness of this unsaturated sand was not independently verified.

The DNAPL used for this experiment was 98\% hydrofluoroether (HFE-7100) produced by the $3 \mathrm{M}$ Company and $2 \%$ methyl caprylate, added to allow for the addition of oil red $\mathrm{O}(0.5 \mathrm{~g}$ in every $1000 \mathrm{~mL}$ total $)$ because standard organic dyes do not dissolve in HFE. At $20^{\circ} \mathrm{C}$, the density of HFE is $1.5 \mathrm{~g} / \mathrm{mL}$ and methyl caprylate is $0.877 \mathrm{~g} / \mathrm{mL}$, 


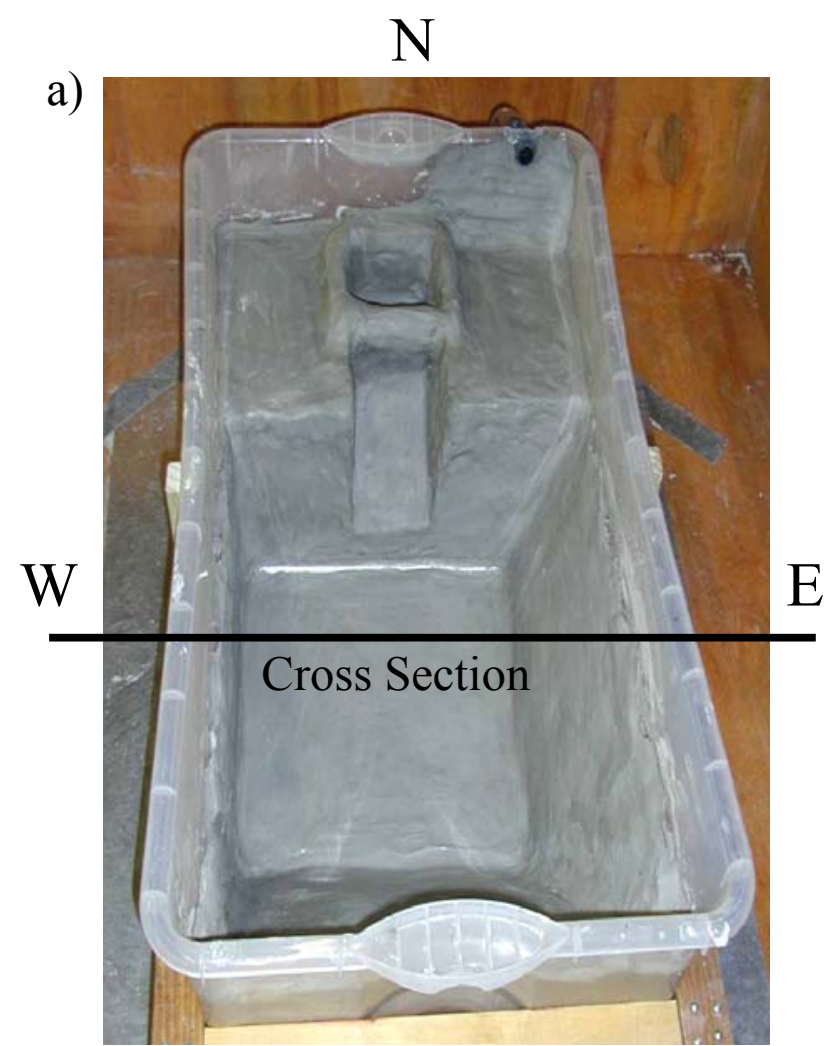

c)

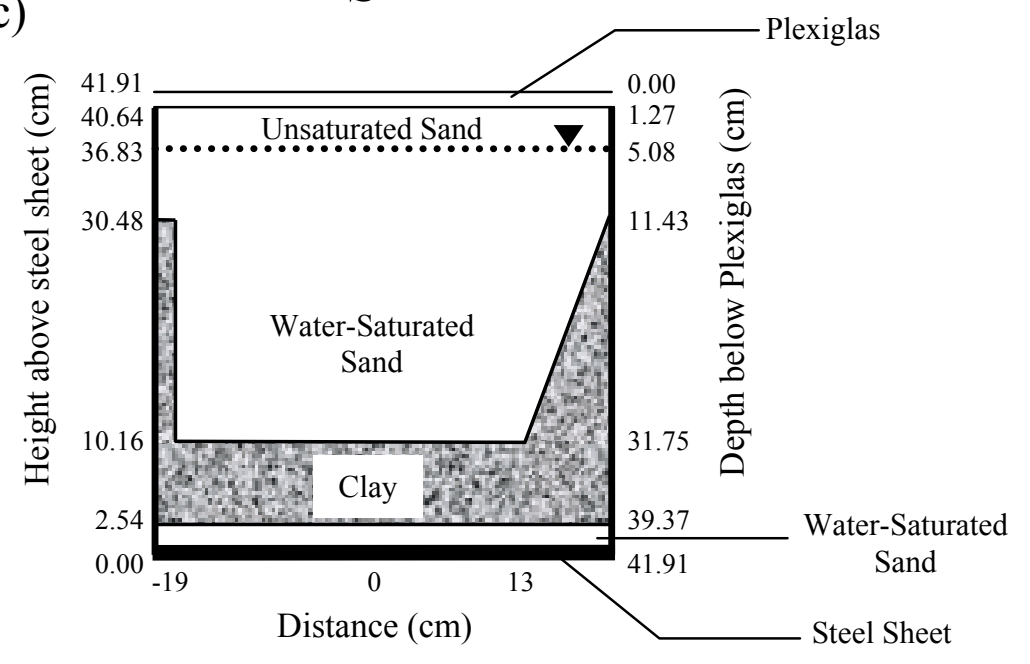

b)

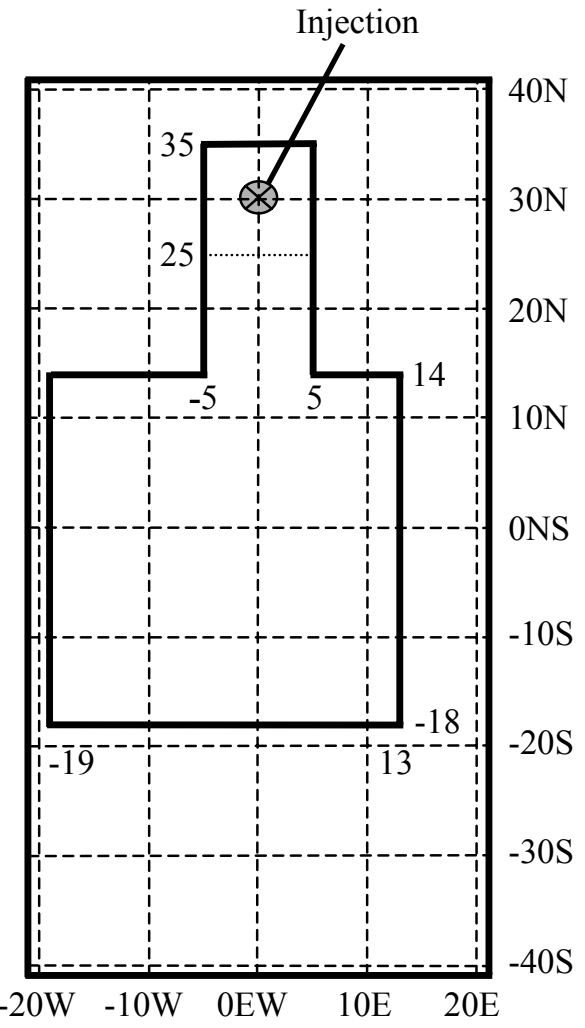

Figure 1: Dimensions of sand tank drawn to scale:
a) overhead photo of unfilled tank;
b) overhead dimensions where total tank area is $42 \mathrm{~cm} \times 82 \mathrm{~cm}$; and
c) cross section looking north. 
a)

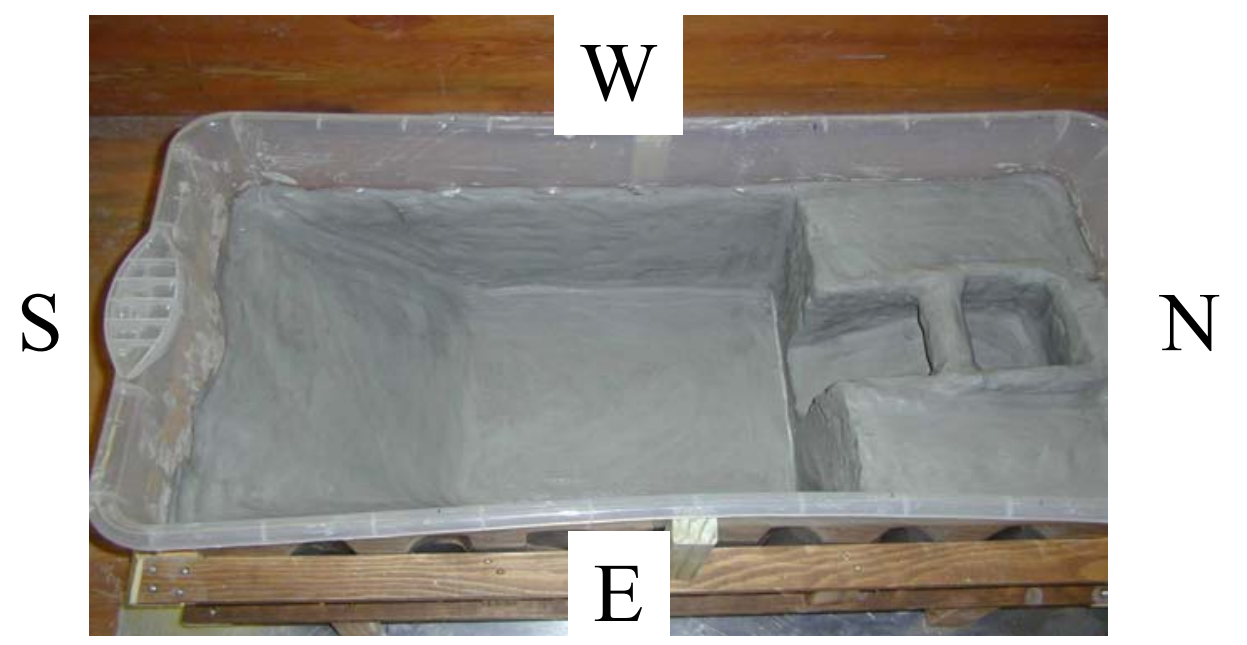

b)

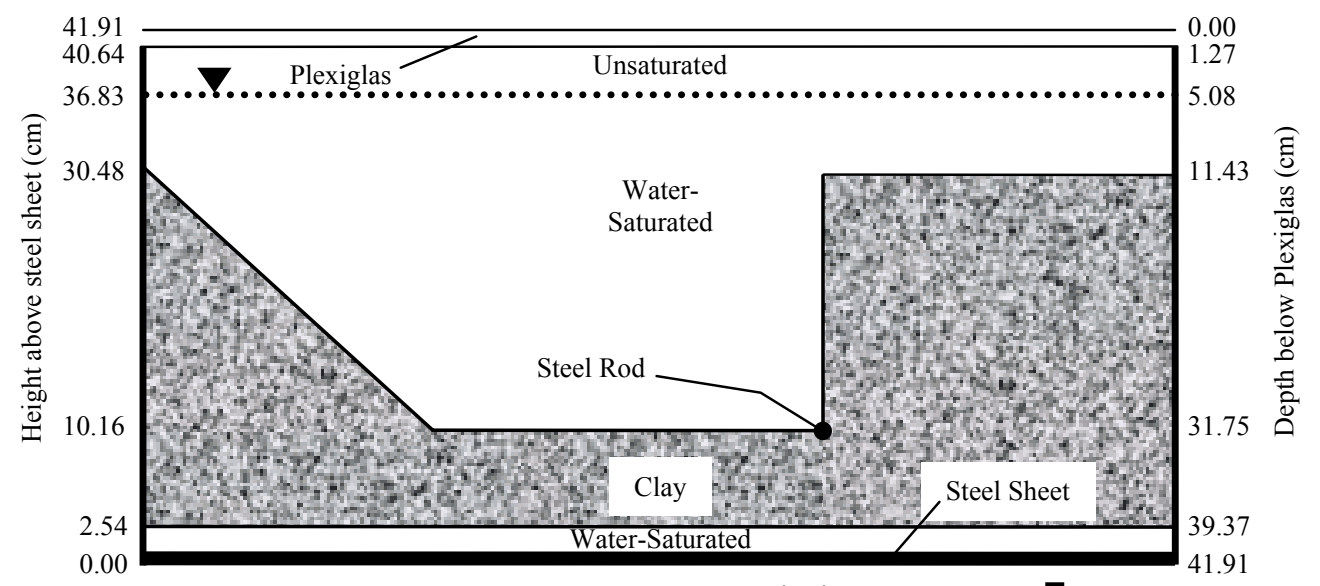

c)

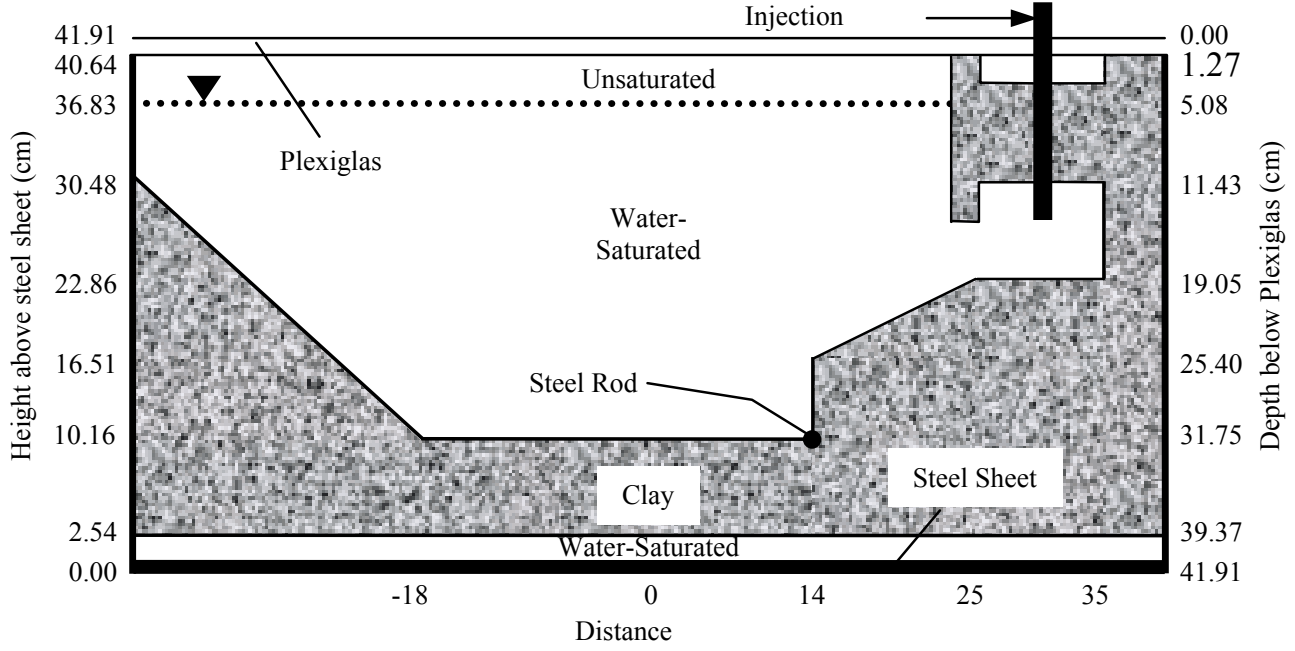

Figure 2: Side view of sand tank with dimensions drawn to scale: a) photo of unfilled tank; b) non-center cross section; and c) center cross section. 


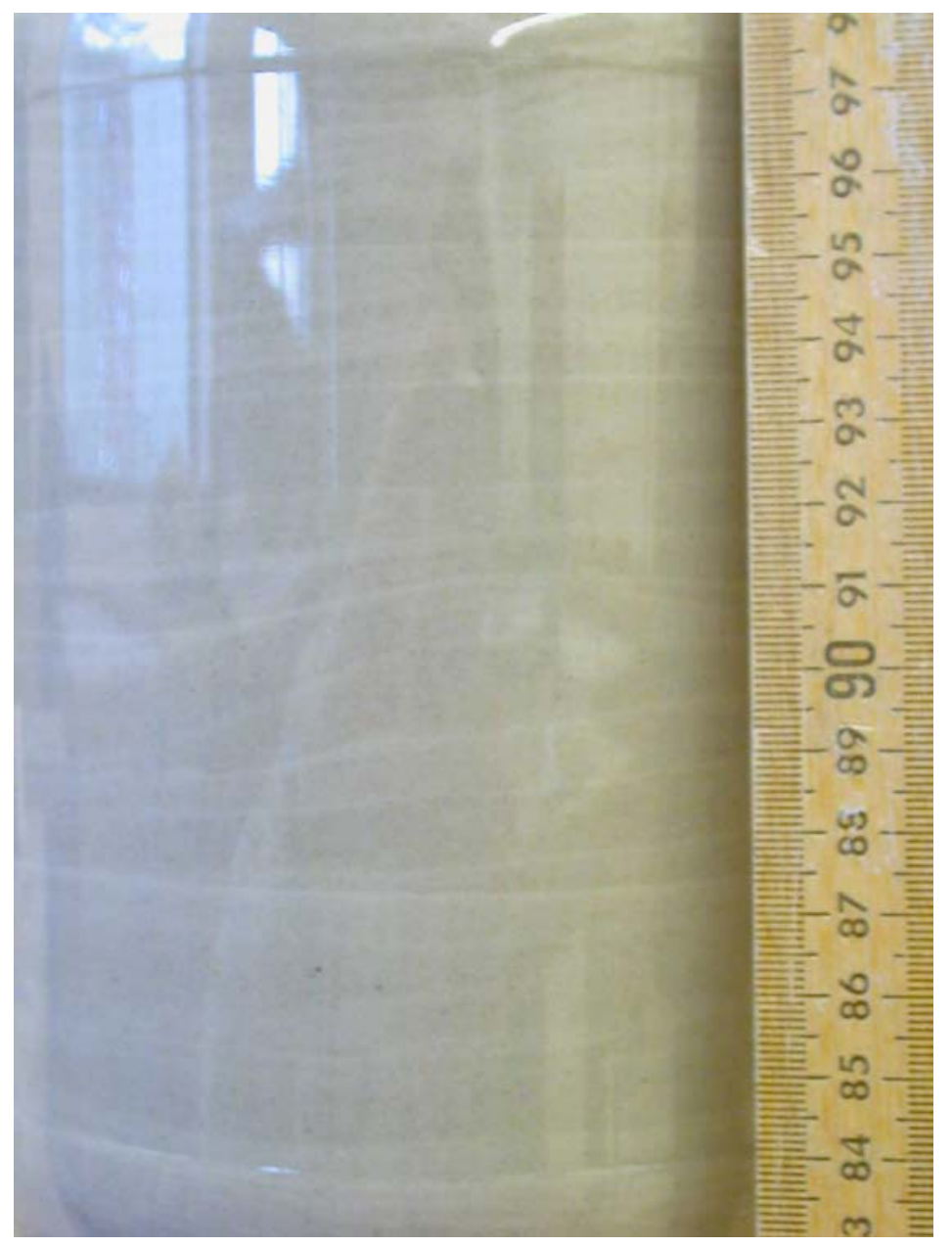

Figure 3: View of sand layering (scale is in $\mathrm{cm}$ ). 
resulting in a density of $1.49 \mathrm{~g} / \mathrm{mL}$ at $20^{\circ} \mathrm{C}$ for the mixture, which was confirmed by direct measurement. The mixture was injected into the tank through a plastic tube, at a constant head of $19.05 \mathrm{~cm}$ above the sand (Figure 4) for 660 minutes. The constant head was maintained by an inlet of dyed HFE, which was constantly circulated via a peristaltic pump, and a free flowing outlet port (Figures $4 \mathrm{a}$ and 5). The whole injection system was sealed to reduce volatile losses and the volume injected was tracked using a graduated cylinder (Figure 5a). The injection zone was surrounded by clay to eliminate leakage of HFE to the surface during injection (Figure 4b). However, upon post-injection disassembly, HFE was seen to have leaked through the clay seal to the north end of the tank. This leak did not occur at the surface, but appeared to follow a fracture in the clay, which allowed the HFE to leak into the narrow space between the clay and the plastic walls of the tank.

GPR data were collected using a Geophysical Survey Systems, Inc. (GSSI) SIR10A unit with a 1.5 gigahertz $(\mathrm{GHz})$ antenna. Geometric control was maintained using a track system and the pull rate of the antenna was maintained at a relatively constant rate using a motorized pulley system (Figure 5). Pre-injection and post-injection GPR data were collected at 1-cm increments. During the injection, GPR data were continuously collected at various locations and times that provided the most information on the DNAPL movement. All post-injection GPR data presented in this paper were collected at 60 hours after the end of the HFE injection period. Analysis of additional post-injection GPR data indicated that no HFE movement was occurring at any time greater than 12 hours post-injection.

After the final GPR data were collected, clear acrylic core tubes were pushed into the tank and withdrawn for visual analysis and quantitative measurement of DNAPL saturation (Figure 6). The sand/clay interface at the bottom of the tank created a seal via the clay and a break in suction via the lower sand, which allowed for easy removal of the cores. The cores were cut into precise increments, weighed, dried, and re-weighed. The known volume of the core and the final mass of the sand, with a known specific gravity, allowed for the calculation of porosity. Excess mass in the pre-dried core, above the mass attributed to the sand and water based on the porosity, could be attributed to the heavier-than-water HFE.

\section{GPR Data}

GPR data were collected in a north-south (Figures 7 and 8) or an east-west (Figures 9 through 15) direction across the tank and can be located using the coordinate system in Figure 1b. A wiggle-trace plot of the center trace is superimposed on the gray-scale GPR profile of the data. A "snapshot" of the tank at approximately 200 minutes after the start of injection at the profiles $10 \mathrm{~N}$ to $20 \mathrm{~S}$, with a 6 -cm interval between each profile shown is presented in Figure 9. The same profiles are shown individually in Figures 10 through 
a)

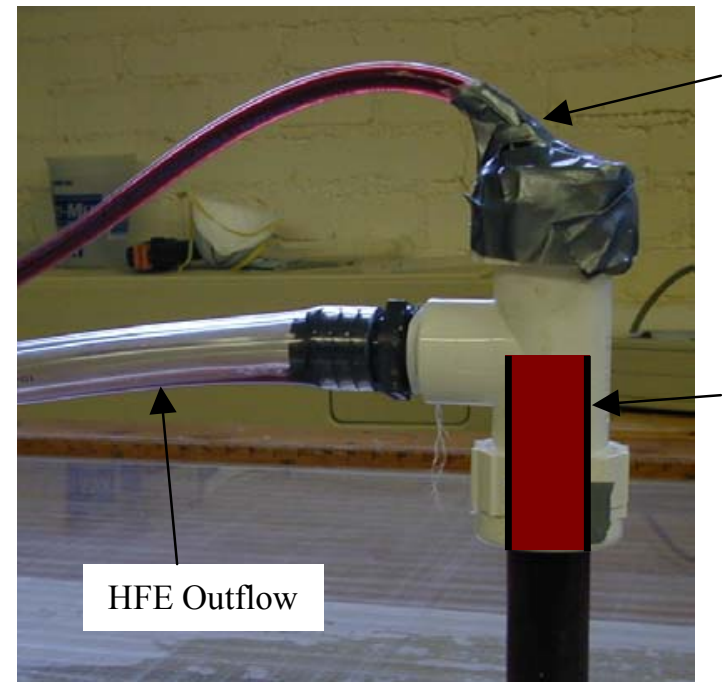

HFE Inflow

HFE held at a constant height by injection tube inside of connector

b)

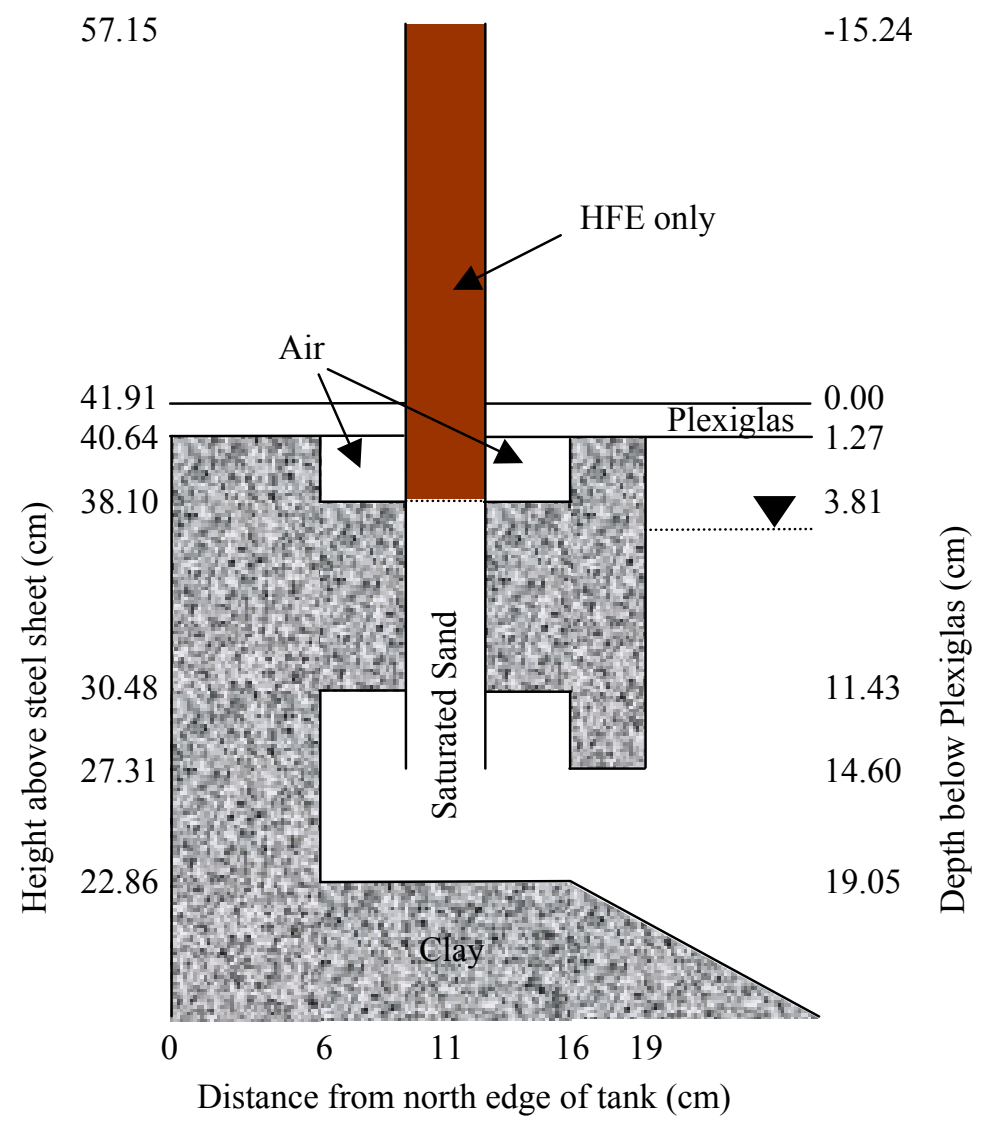

Figure 4: Details of the injection system: a) photo of injection system above the Plexiglas; and b) dimensions of injection system drawn to scale. 
a)

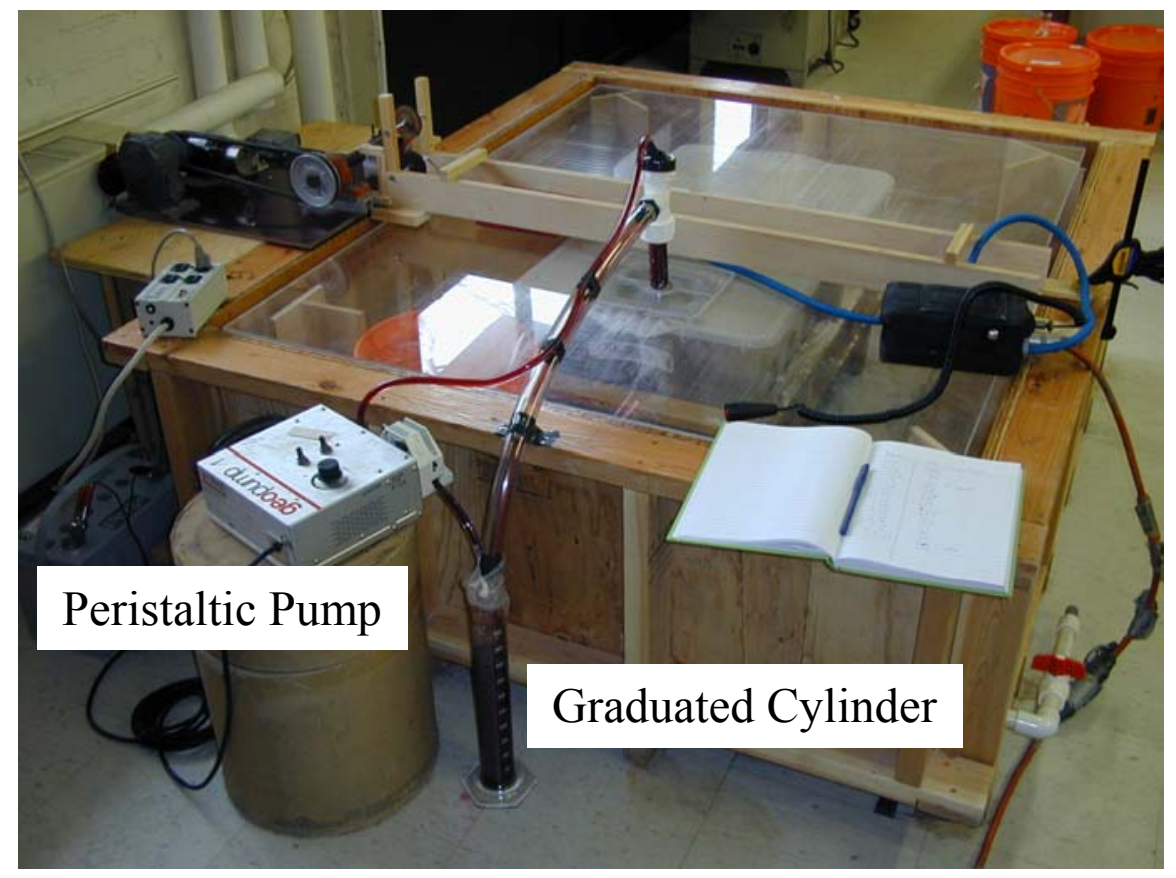

b)

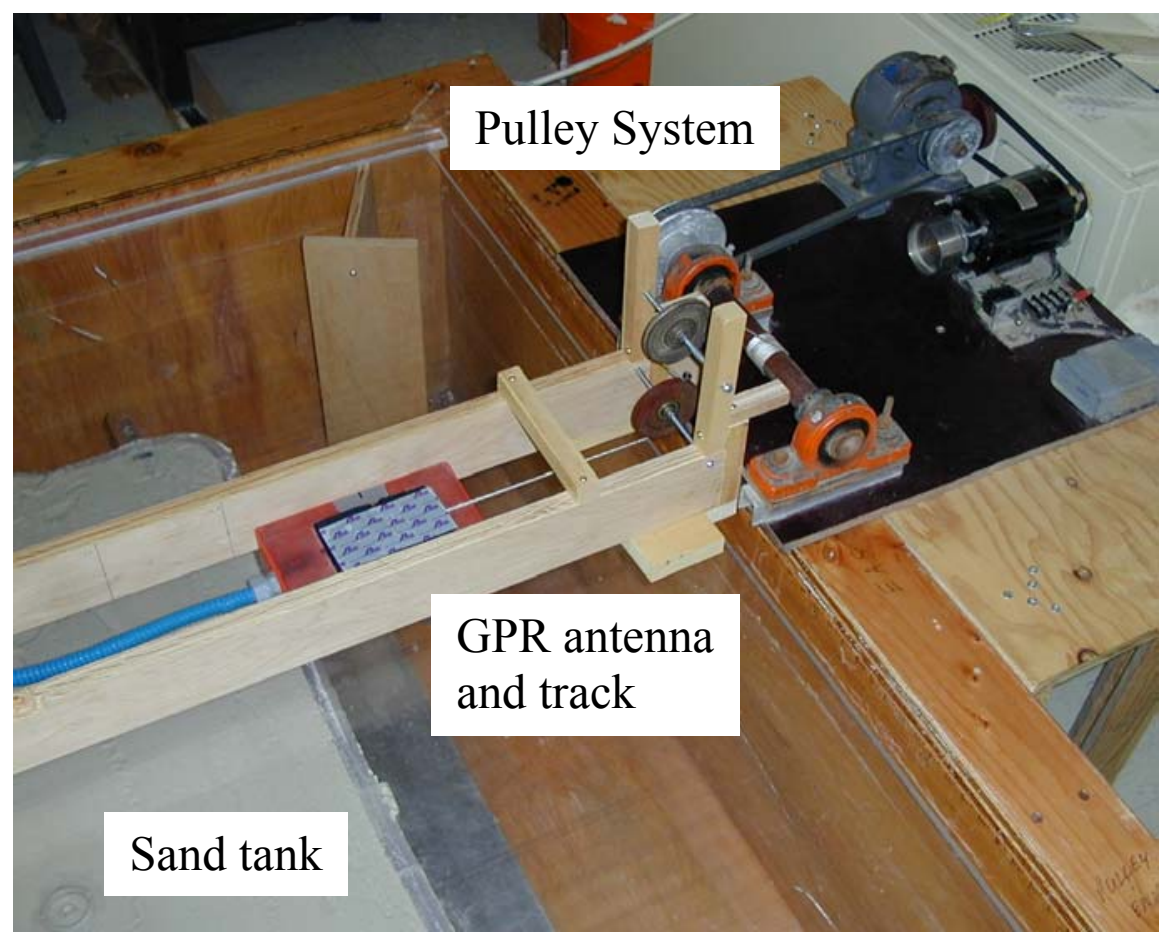

Figure 5: Photograph of: a) sand tank, injection system, and GPR antenna track and pulley; and b) close up photograph of GPR antenna, track, and pulley system. 
a)

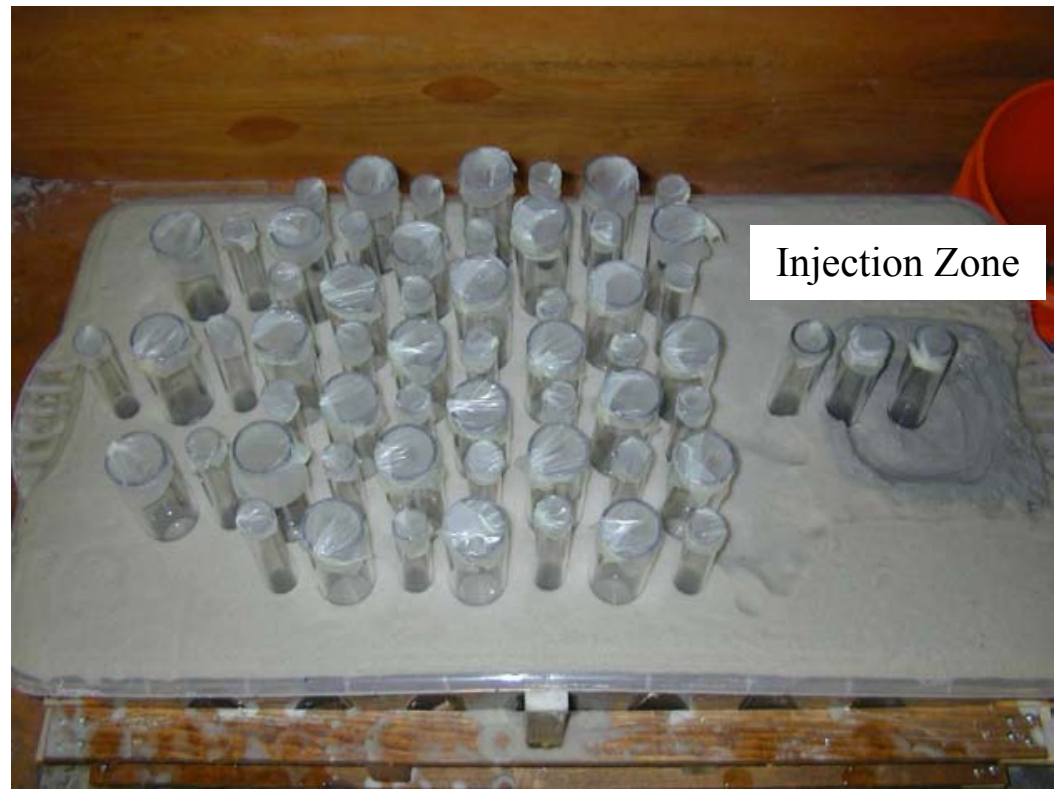

b)

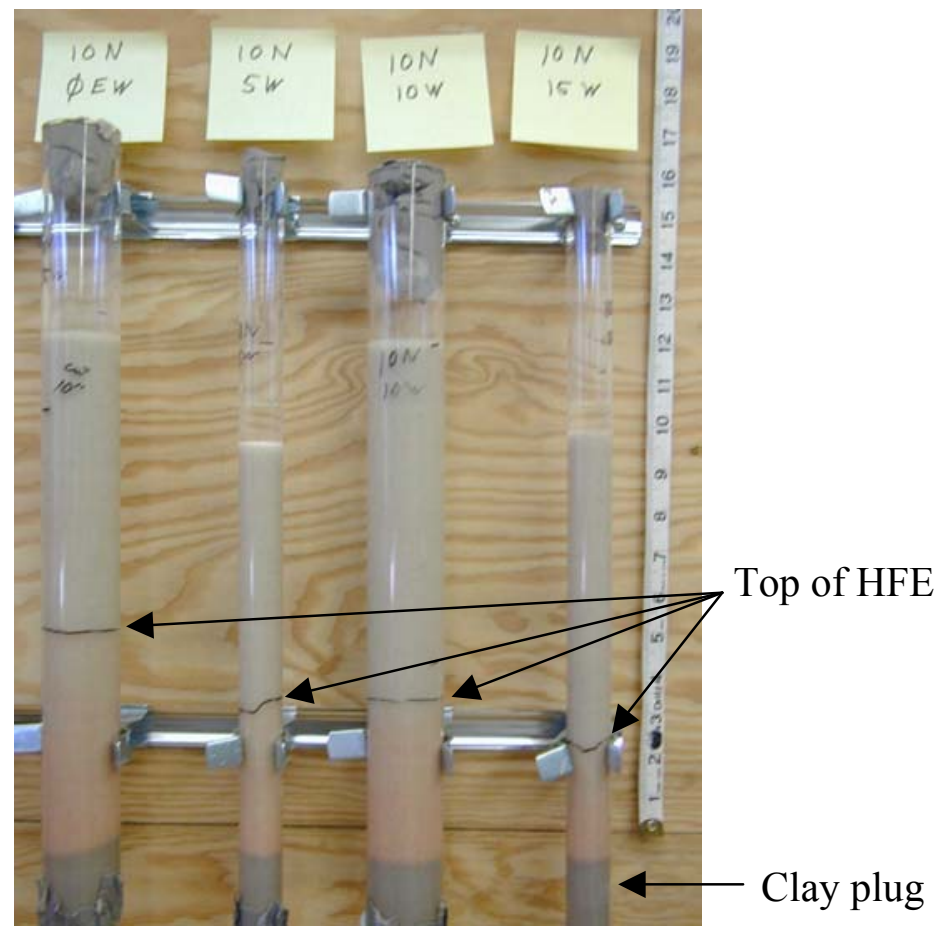

Figure 6: Core tubes: a) within sand tank; and b) withdrawn and mounted. 
a)

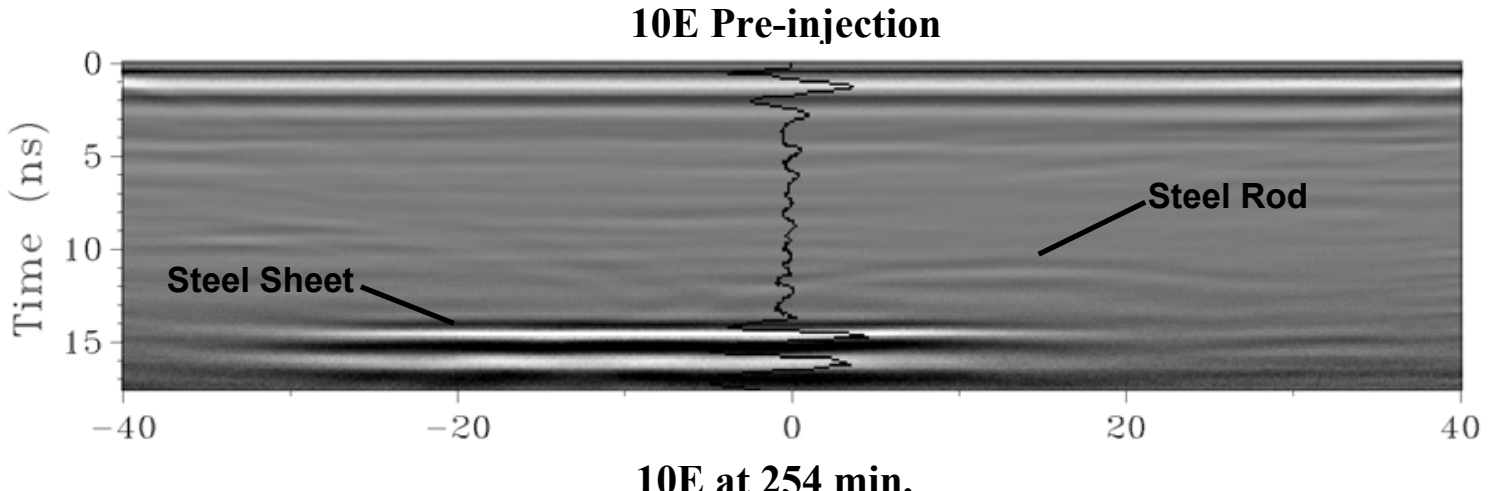

b)

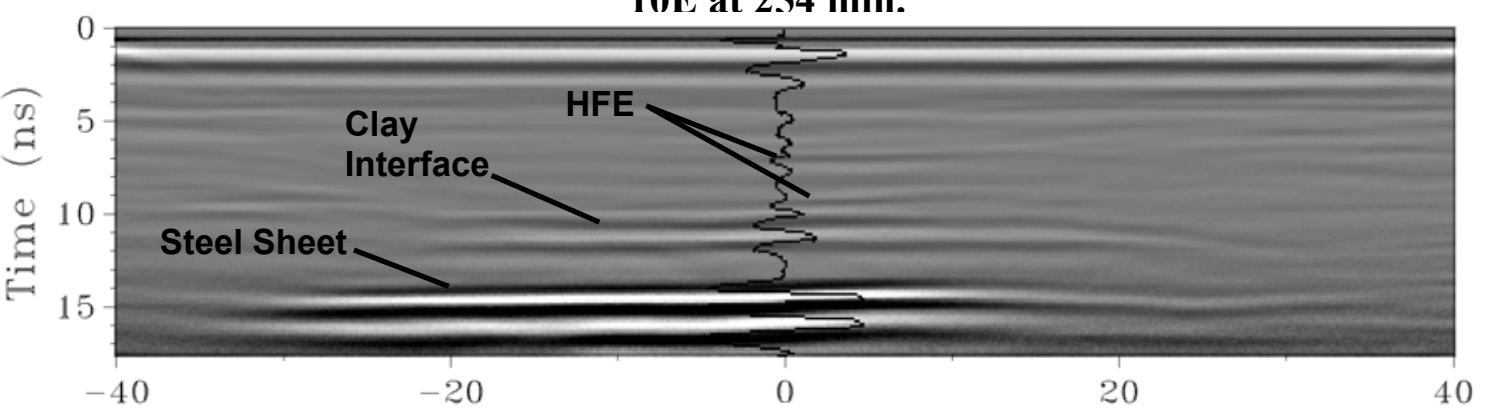

c)

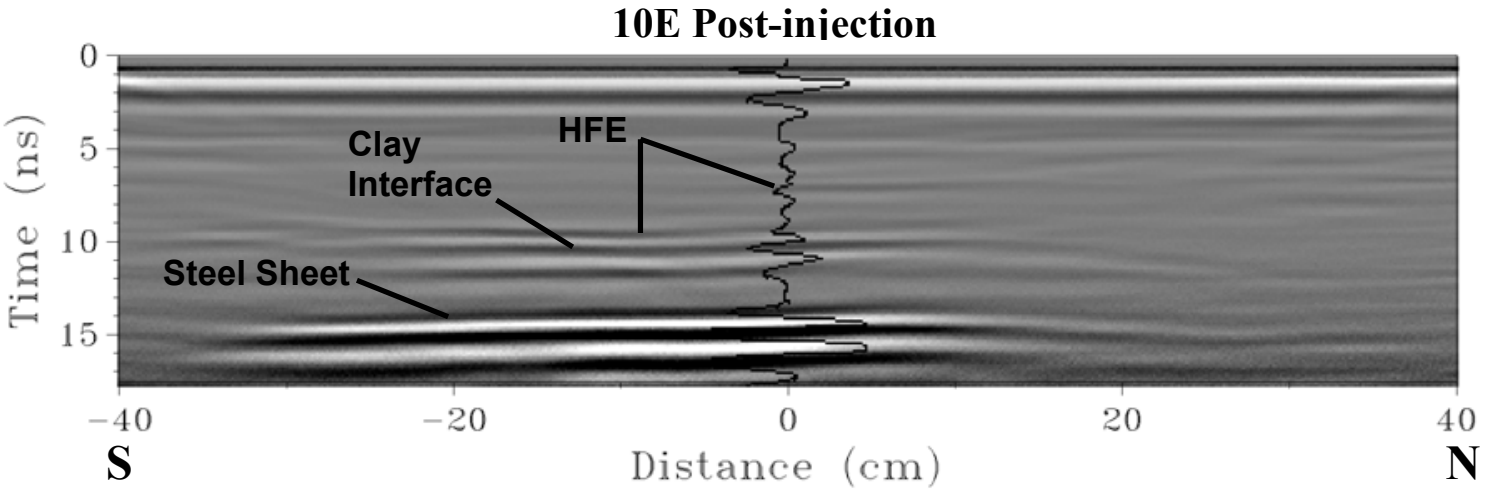

Figure 7: GPR data at various times along 10E, looking west. Negative distances are the south end of the tank and positive distances are the north end of the tank. A wiggle-trace display of the center trace is superimposed on the grayscale profile display. 
a)

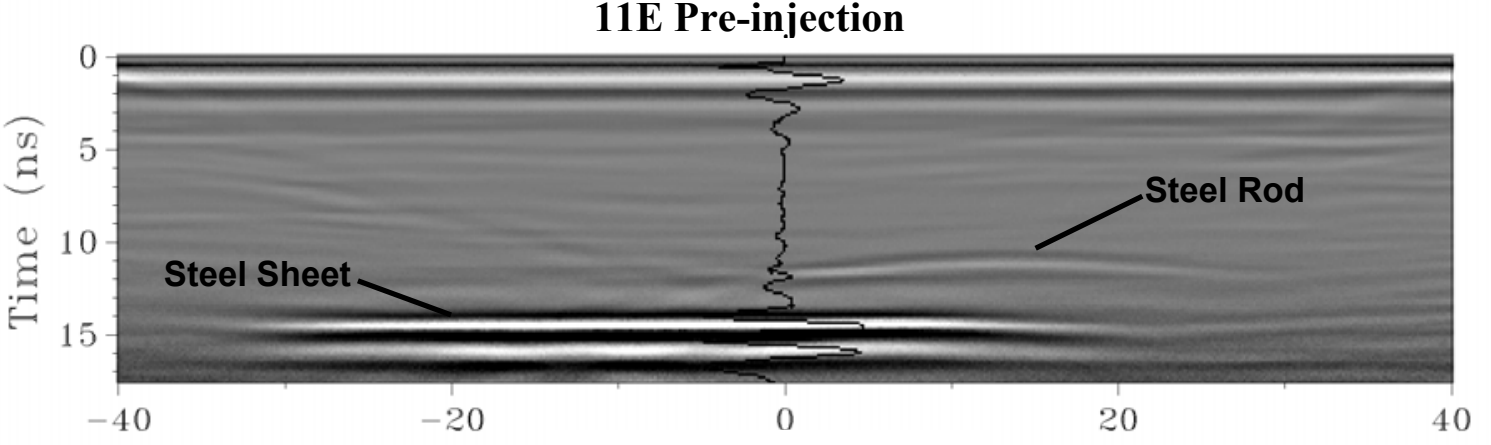

b)

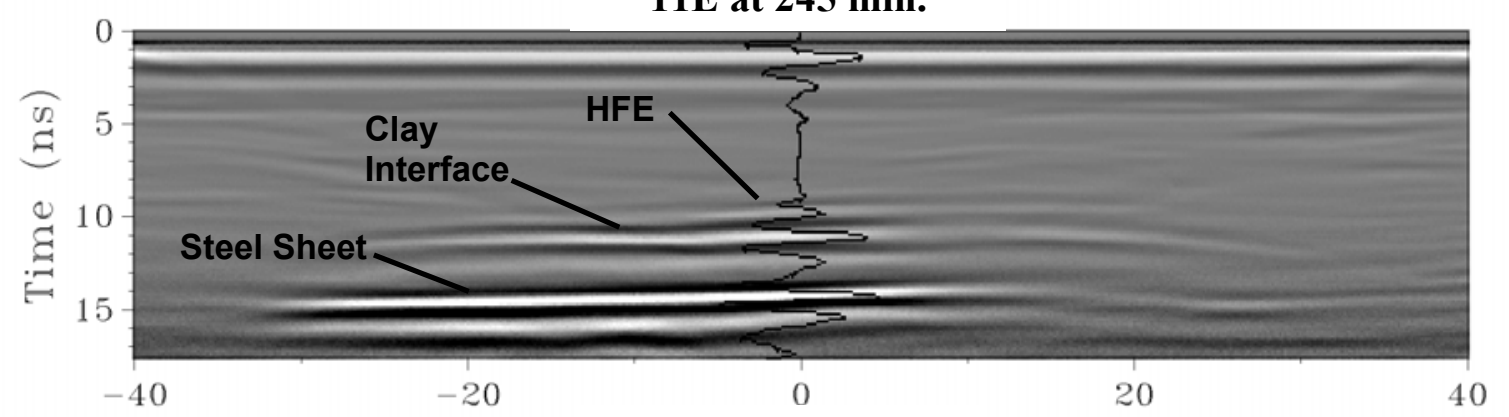

c)

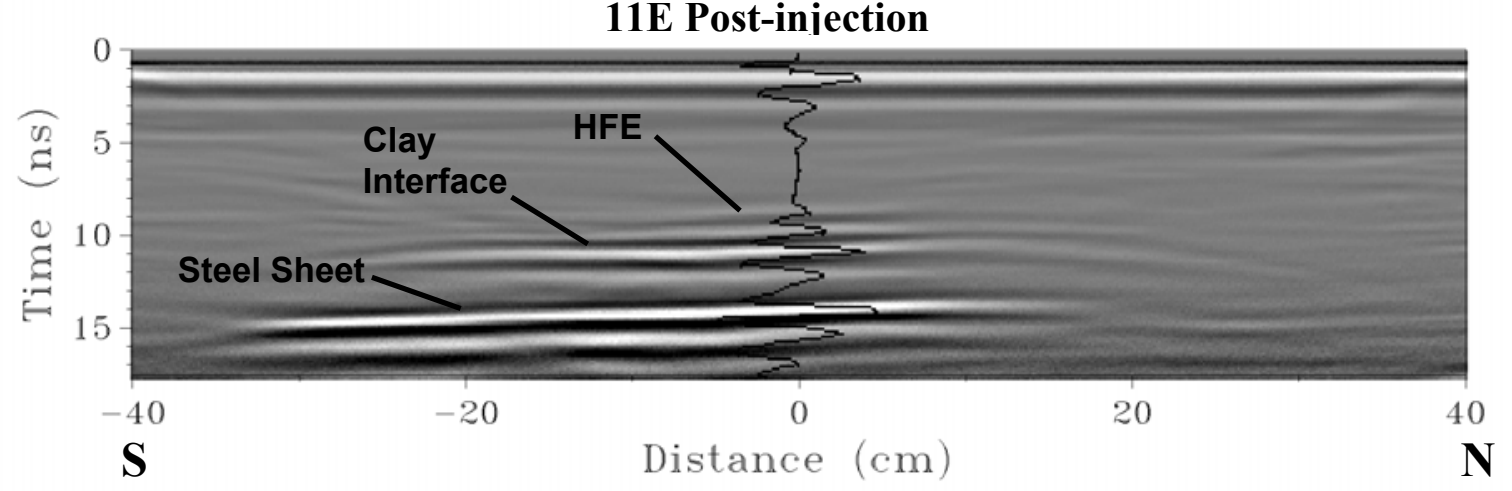

Figure 8: GPR data at various times along $11 \mathrm{~W}$, looking west. 
a)

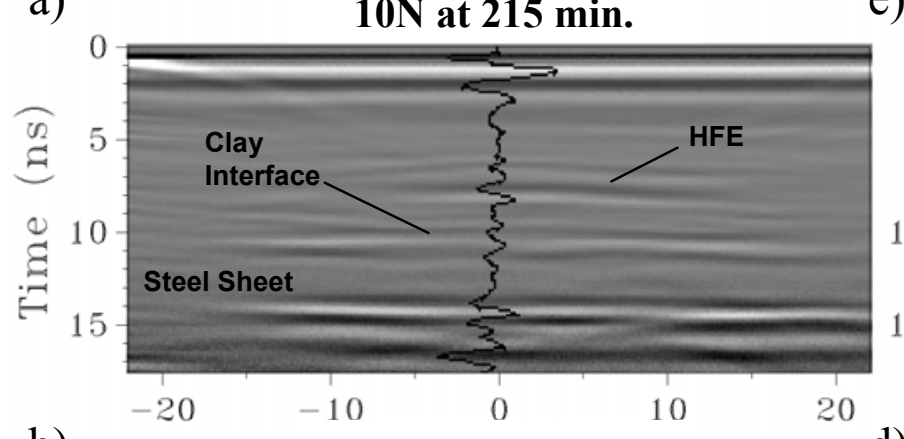

b)

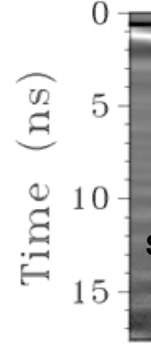

04N at 211 min.

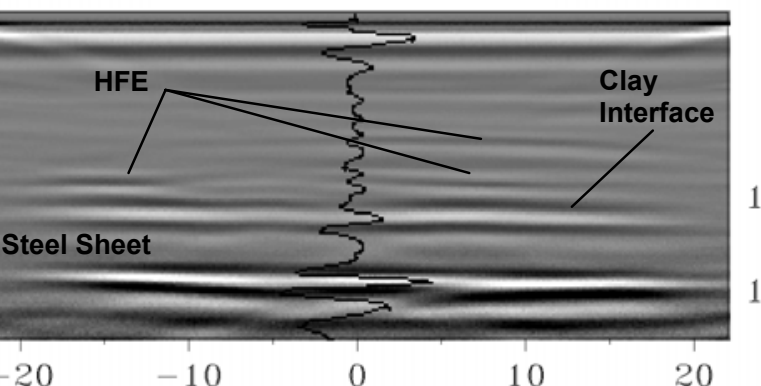

e)

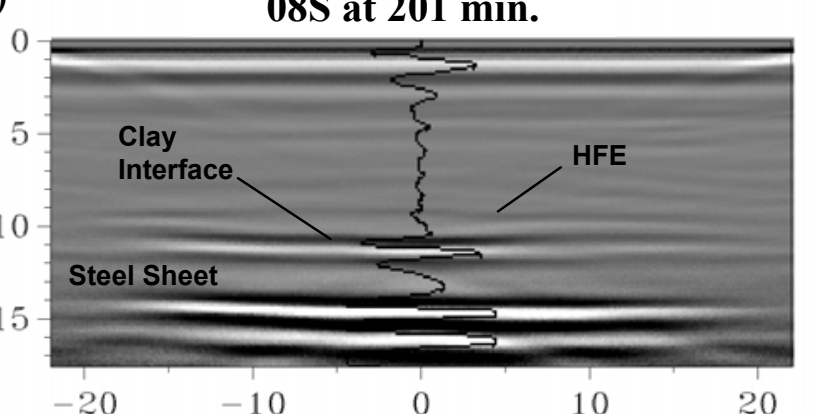

d)

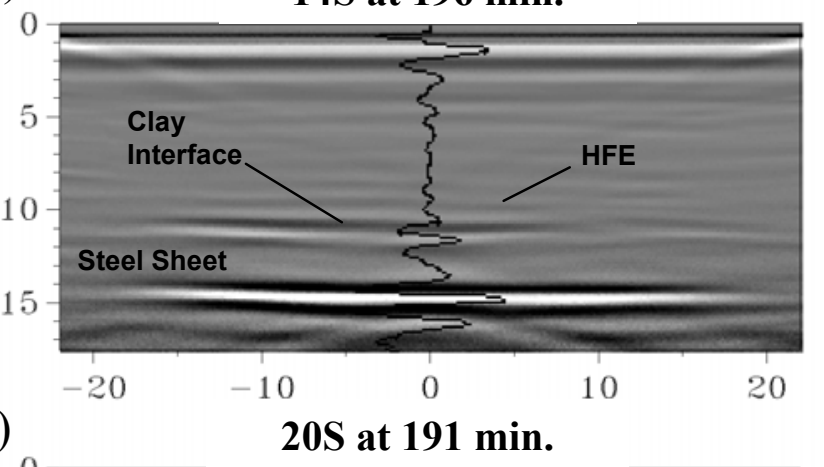

c)

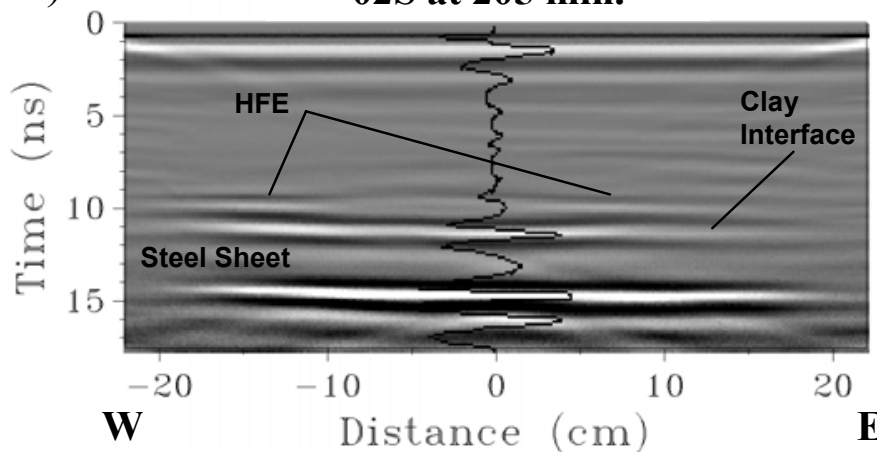

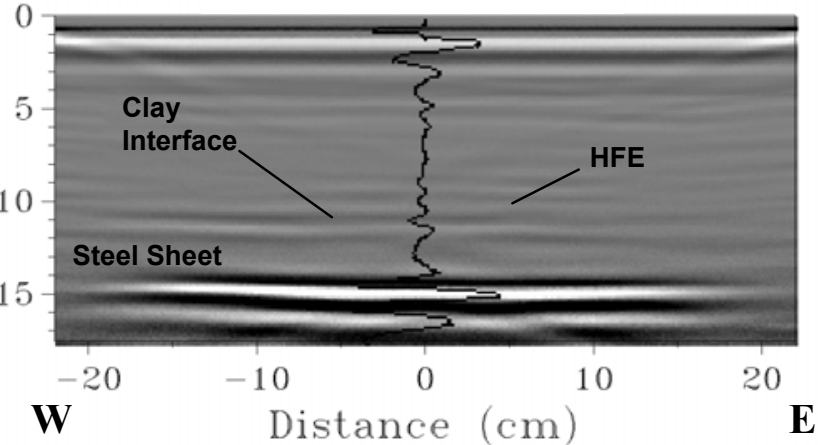

Figure 9: GPR data at various E-W cross sections at approximately 200 minutes, looking north. Negative distances are the west end of the tank and positive distances are the east end of the tank. 
a)

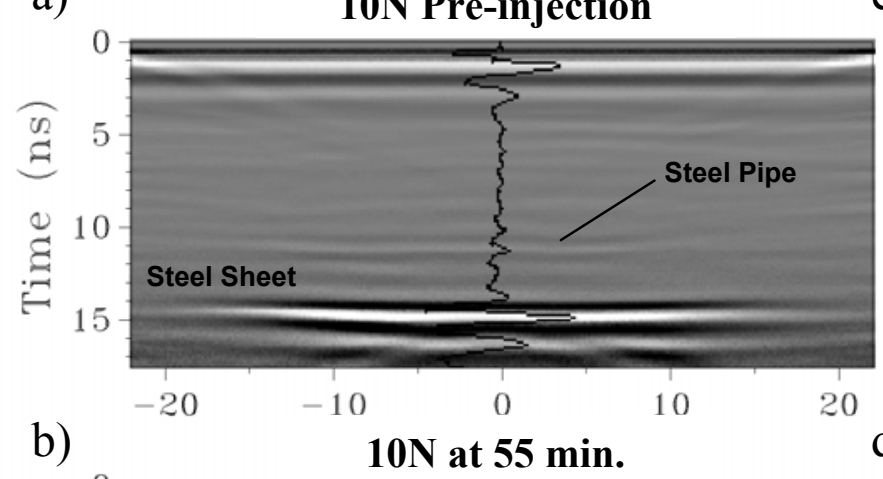

e)

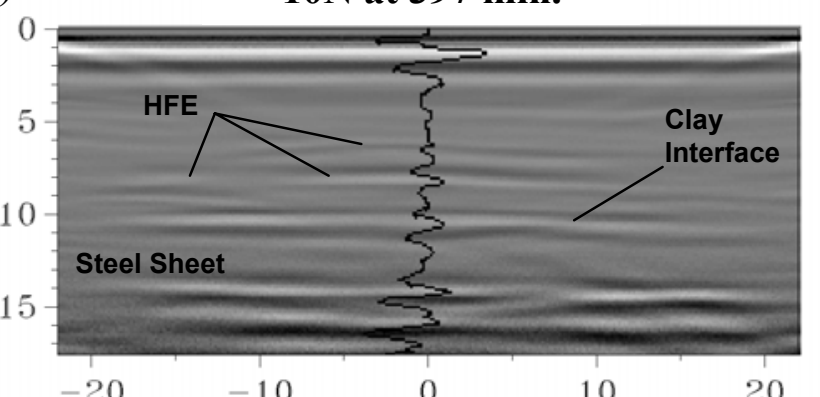

d)
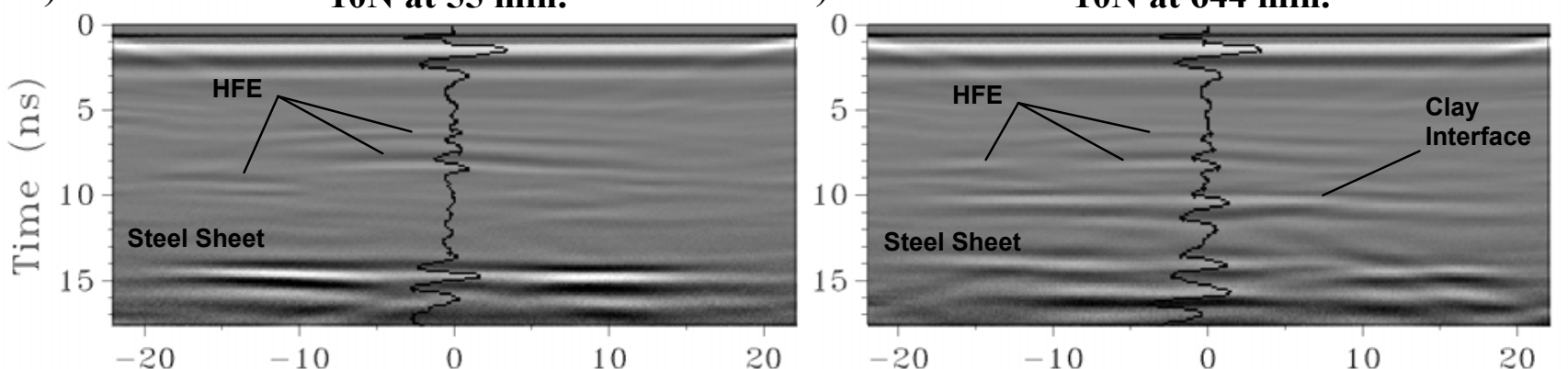

c)

$10 \mathrm{~N}$ at $215 \mathrm{~min}$.

f)
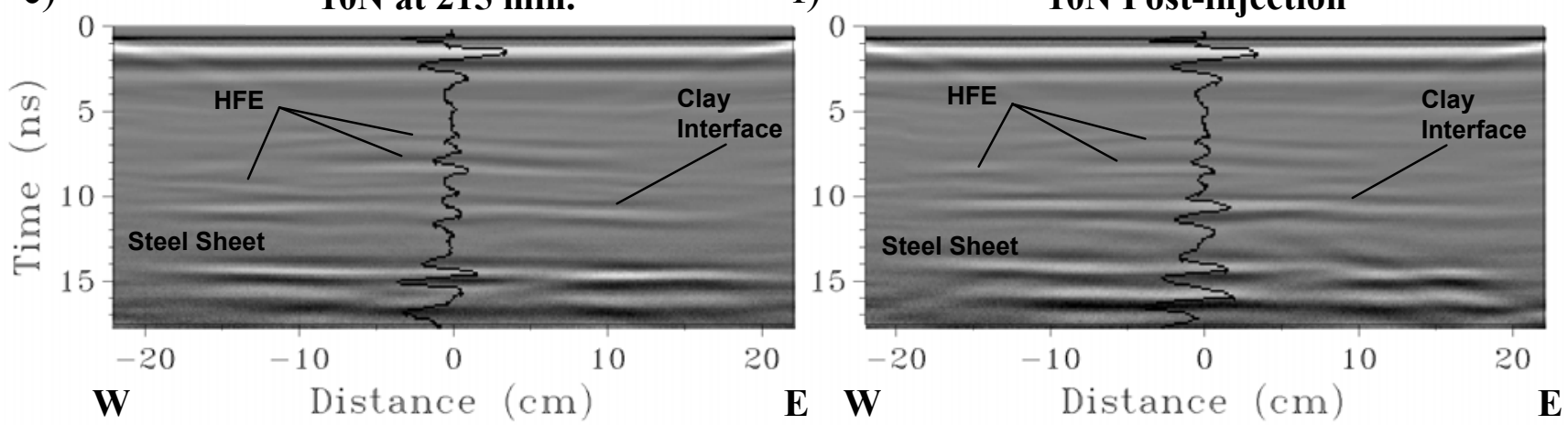

Figure 10: GPR data at various times along 10N, looking north. 


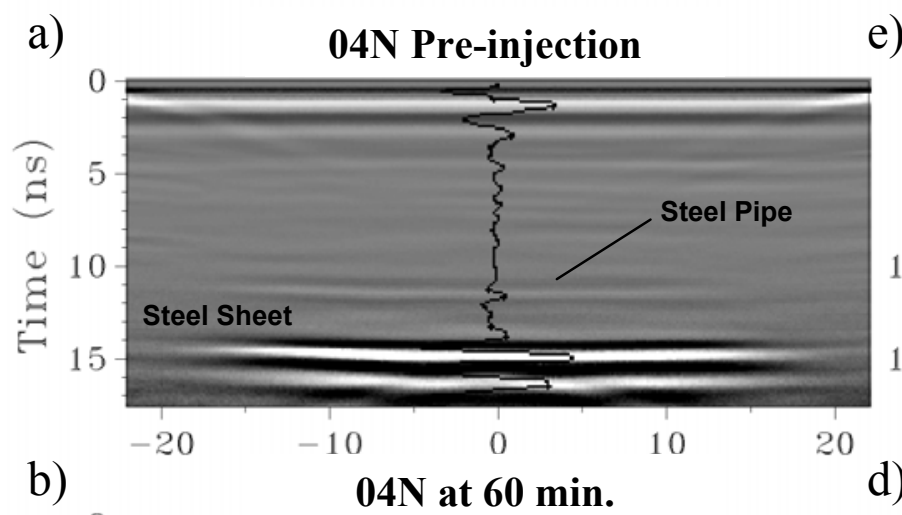

e) $04 \mathrm{~N}$ at $287 \mathrm{~min}$.
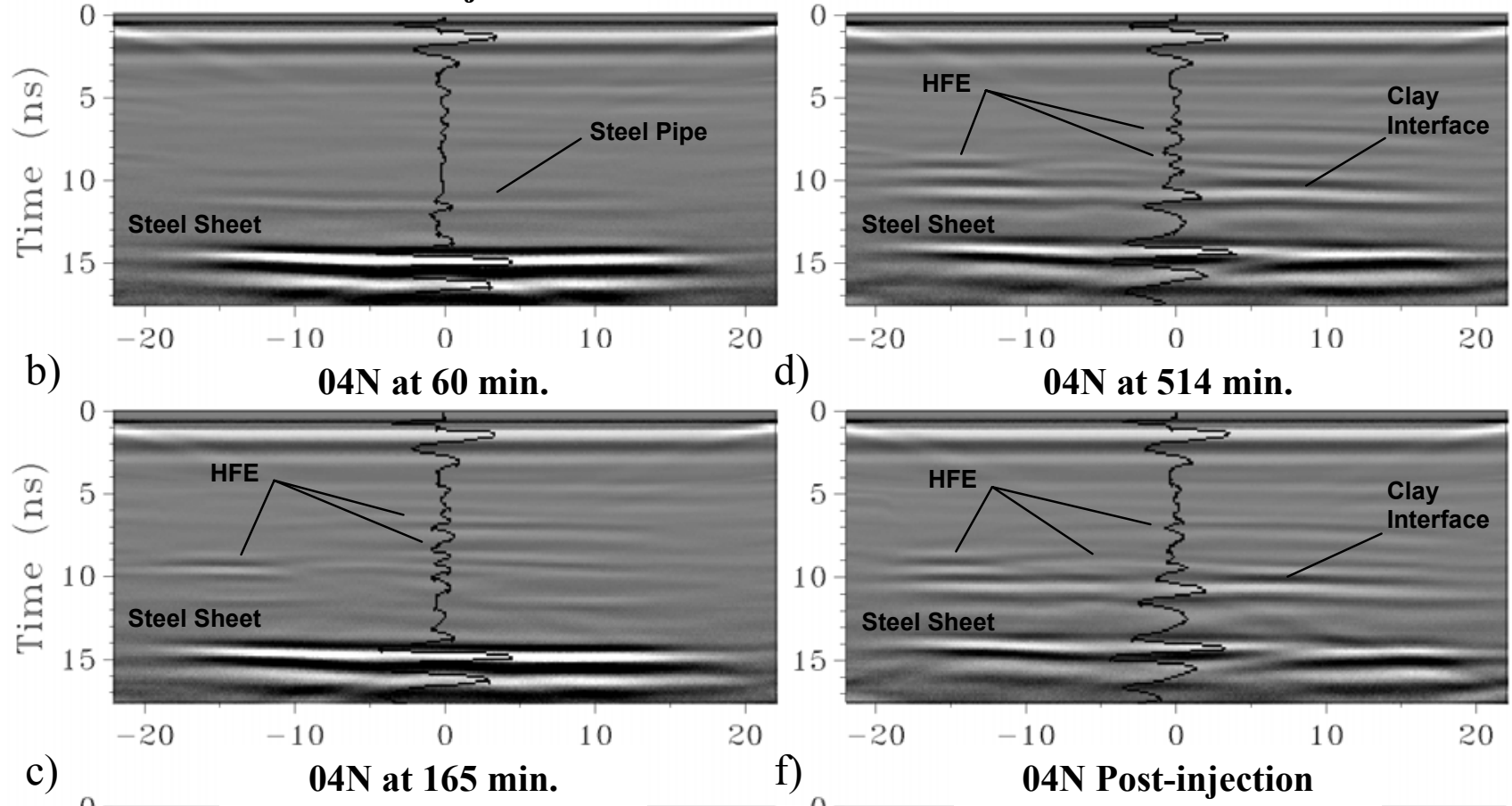

d)
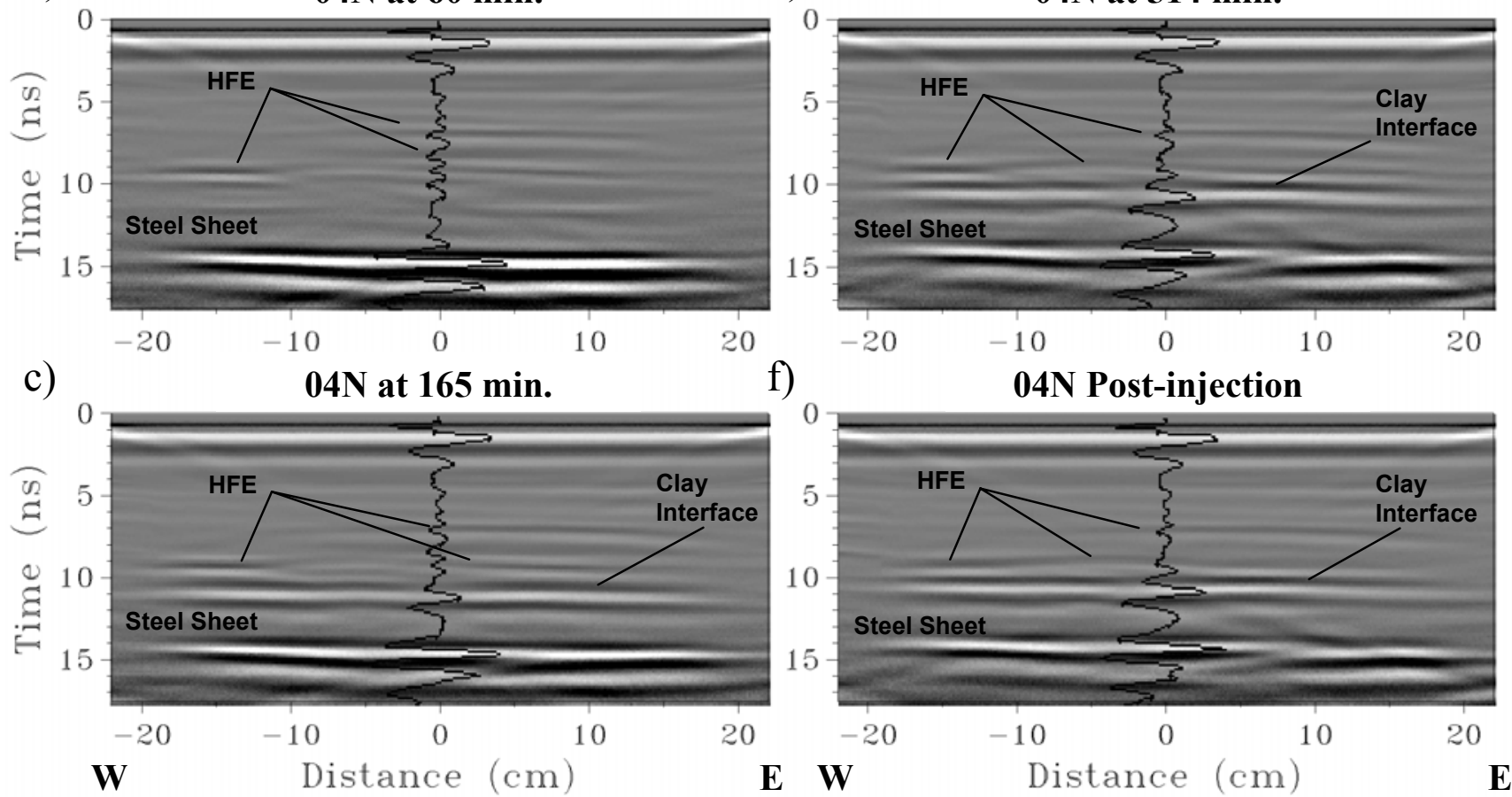

Figure 11: GPR data at various times along 04N, looking north. 


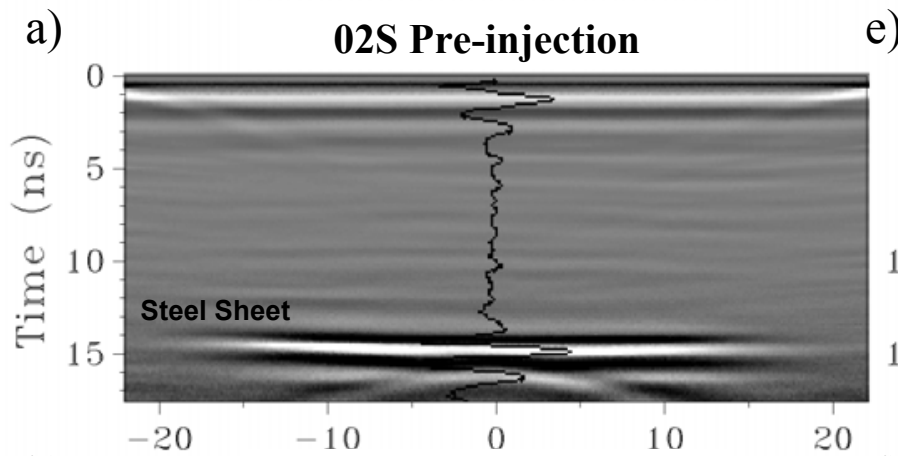

e)

$02 \mathrm{~S}$ at $280 \mathrm{~min}$.
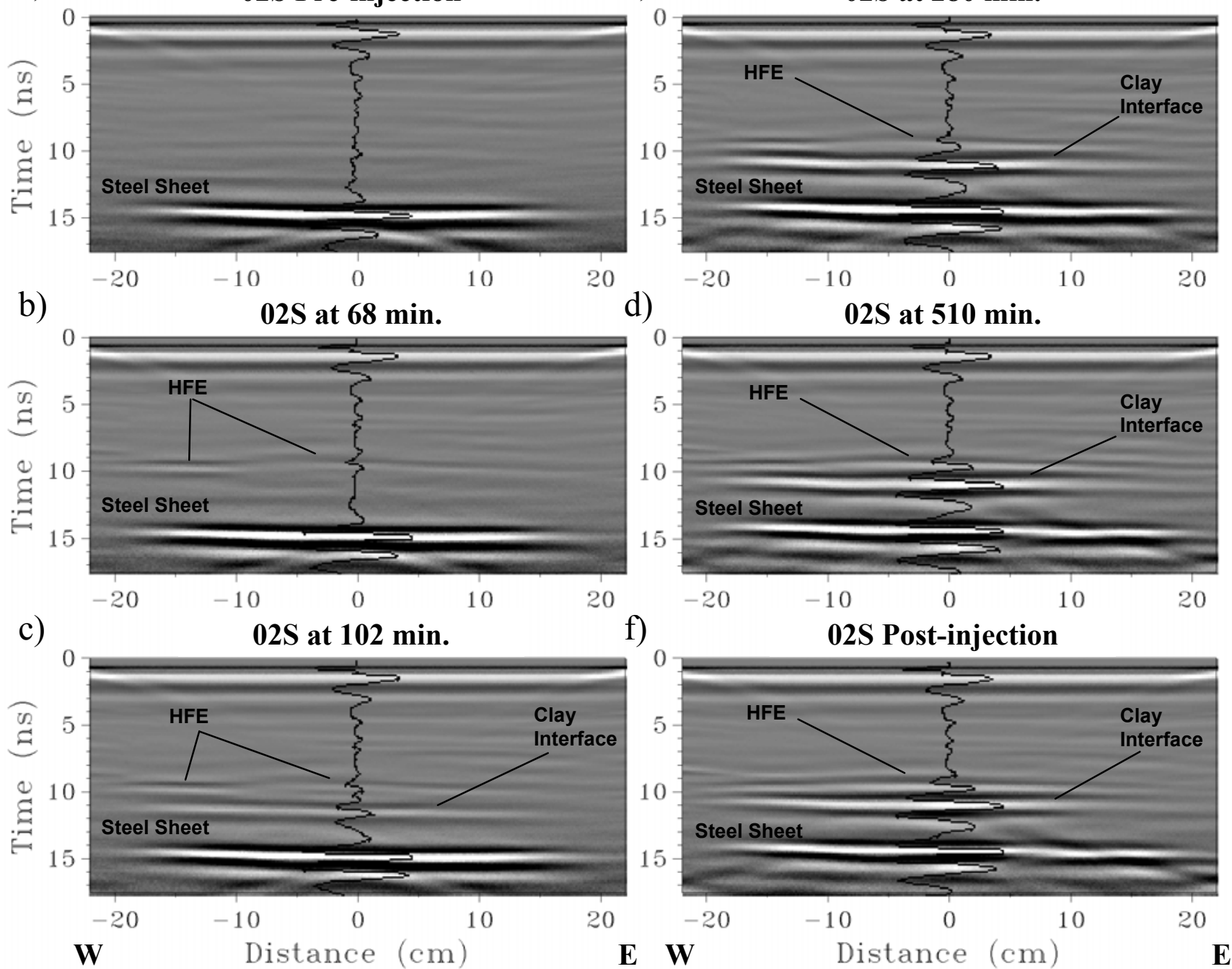

Figure 12: GPR data at various times along $02 \mathrm{~S}$, looking north. 

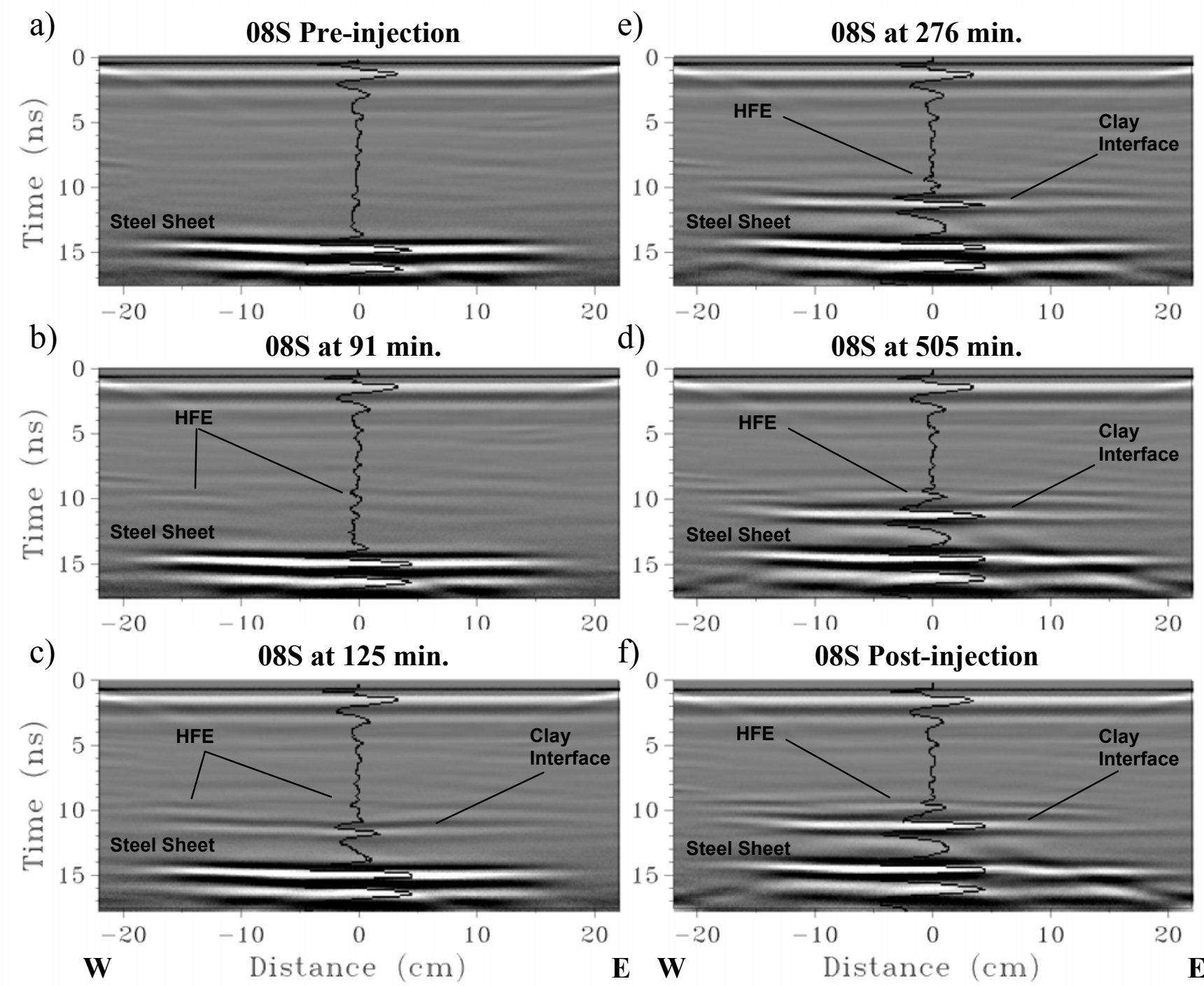

Figure 13: GPR data at various times along 08S, looking north. 
a)

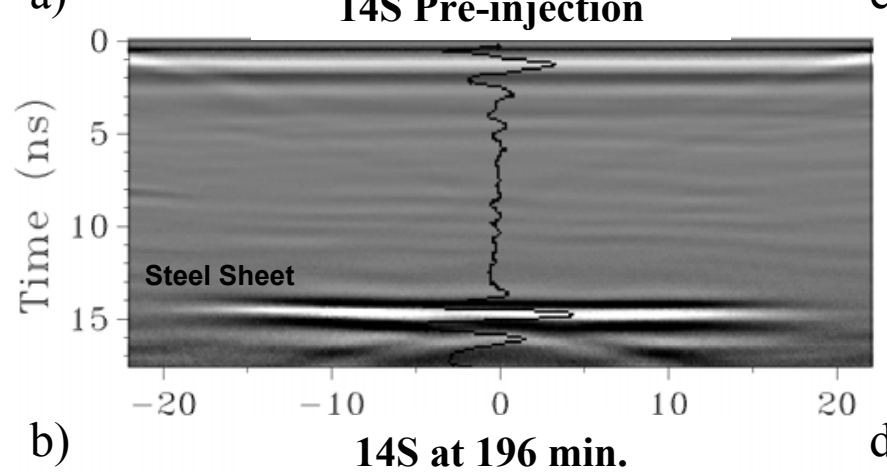

e)

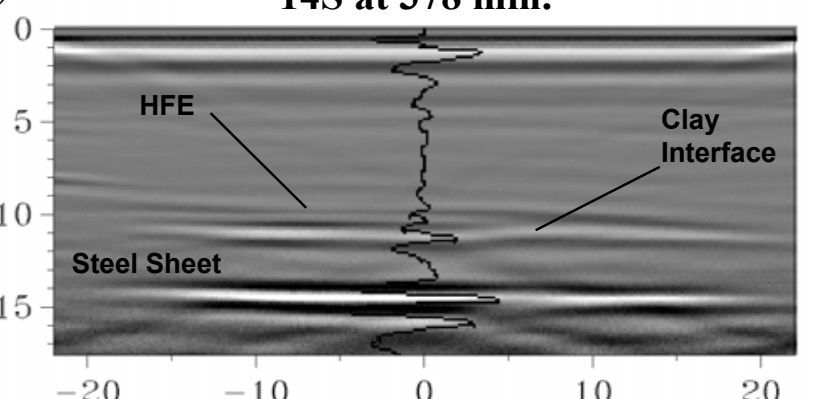

d)
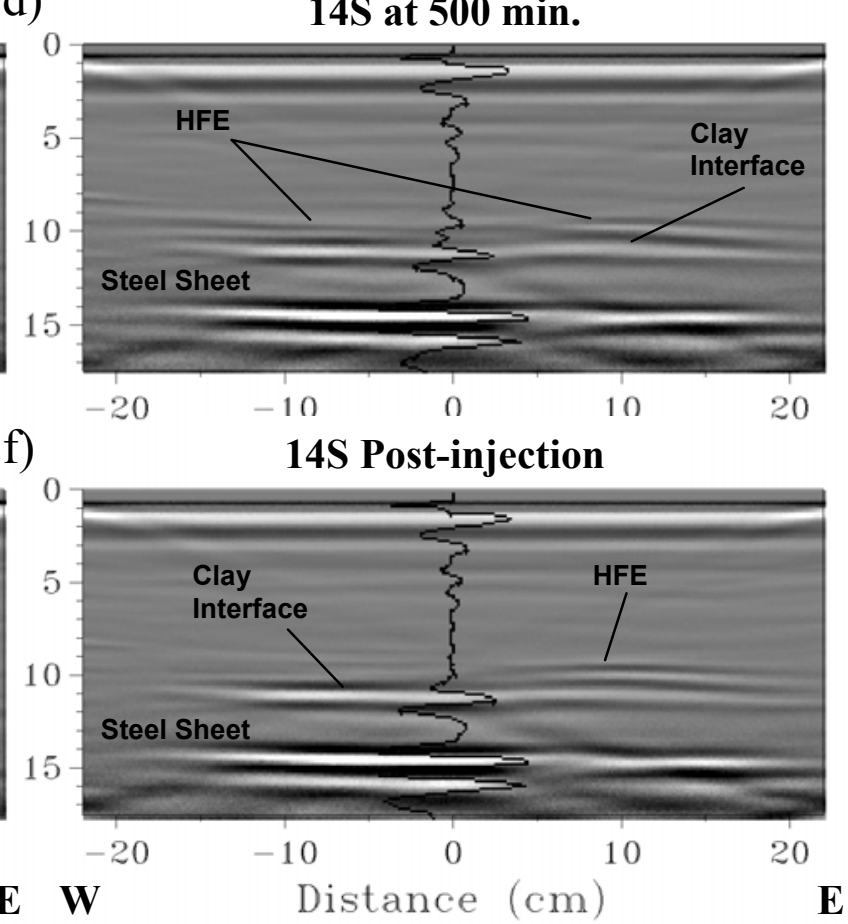

Figure 14: GPR data at various times along 14S, looking north. 

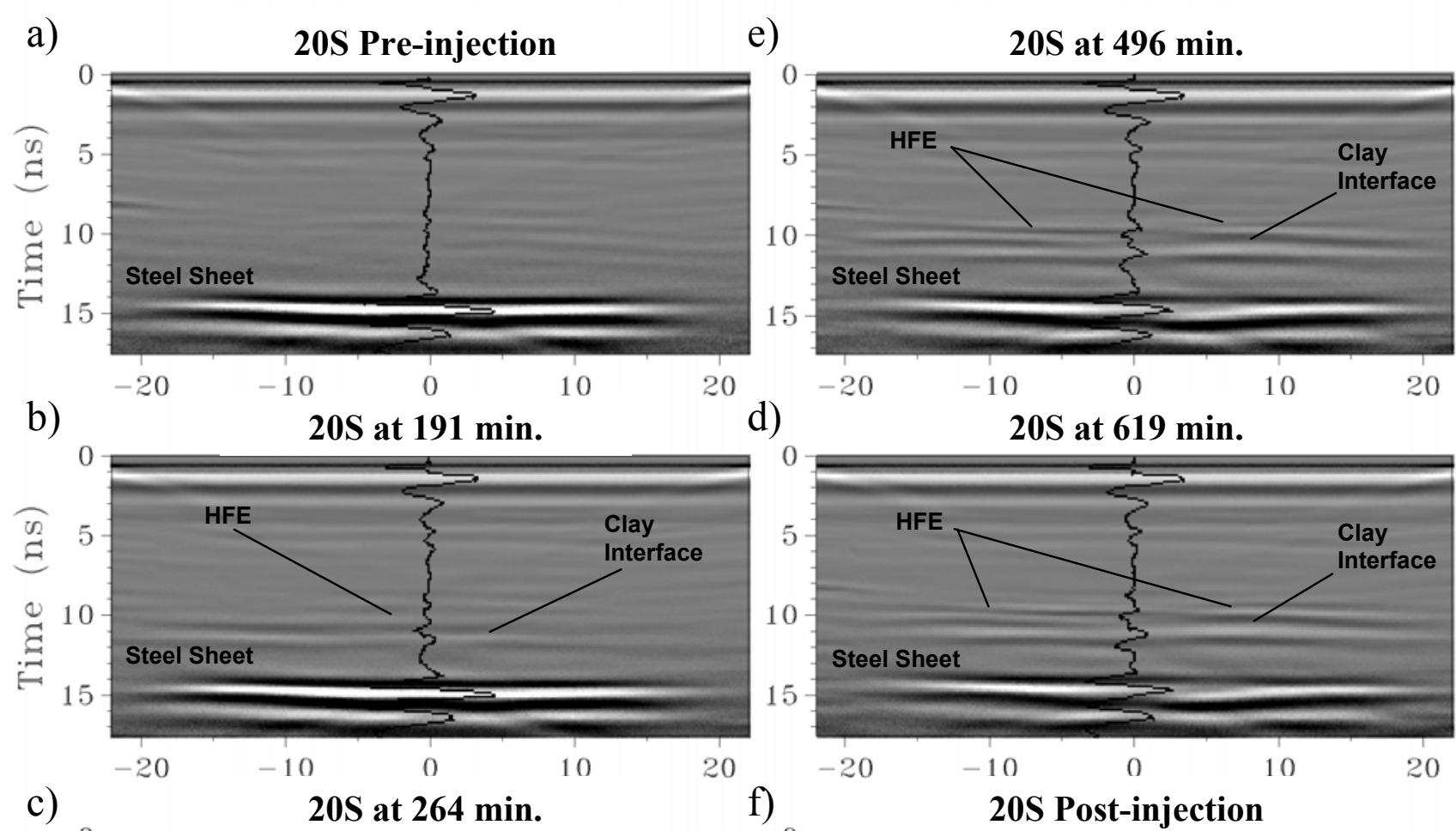

d) $20 \mathrm{~S}$ at $619 \mathrm{~min}$.

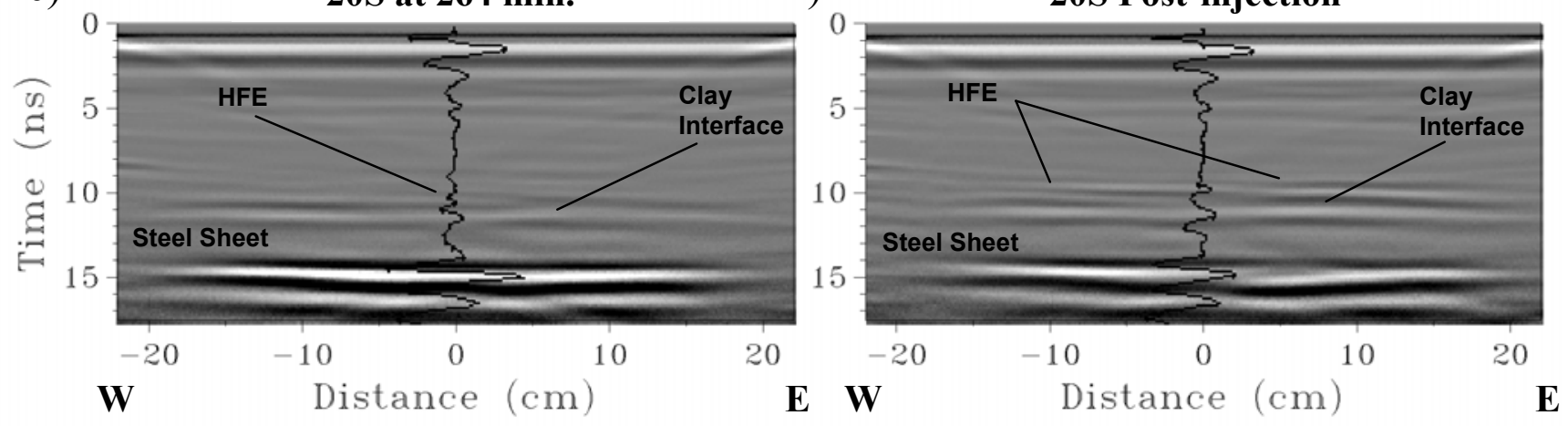

Figure 15: GPR data at various times along 20S, looking north. 
15 with pre-injection, post-injection, and intermediate time data when significant changes in the GPR image occur.

Several key features are consistent in all of the 2D GPR images. Differences in these key features through time are created by HFE flowing into the initially water-saturated sand. Time zero in all the GPR images represents the top of the Plexiglas. A steel sheet is located at $31.75 \mathrm{~cm}$ below the top of the Plexiglas and occurs at a time of approximately 14 nanoseconds (ns) in the pre-injection GPR images. The steel sheet cannot be seen as distinctly in the north end of the tank because the greater electrical conductivity of the thicker clay attenuates the GPR signal. This same influence is seen at the south, east, and west sides of the tank as the clay thickens, but is not as great in extent. The addition of HFE creates a "pull-up" effect for the reflection of the steel sheet, as seen most dramatically in Figures $7 \mathrm{c}$ and $8 \mathrm{c}$, where the reflection slopes to the south. The reflection occurs sooner on the north end due to the greater volume of HFE close to the injection zone. The GPR waves travel faster through the water/HFE/sand mixture than the water-saturated sand and the travel time decreases with increasing HFE volume; thus, the use of time for the $y$-axis and not depth. The arrival time of reflected GPR energy, seen as a change in gray coloration, is controlled by the two-way travel time required for the energy to leave the antenna, be reflected by the subsurface material, and travel back at the antenna.

Additional key features in the GPR images include reflections from the sand/clay interface with HFE in the sand, HFE inflow, and a steel rod. Reflections of the GPR energy occur where there is a change in electrical conductivity and/or dielectric permittivity. Reflections from the steel sheet and steel rod occur due to their greater electrical conductivity. The clay is slightly more electrically conductive and has a slightly different permittivity than the water-saturated sand, but as seen in the preinjection images, this contrast is not great enough to produce a strong reflection. Because HFE is non-conductive and has a much lower permittivity than water, when HFE flows into the sand at the sand/clay interface, the resulting contrast highlights this interface (Figures 7 through 15). Reflections that occur within the sand before the reflection of the sand/clay interface indicate inflow of the HFE. At 10N and 04N (Figures 10 and 11), these reflections are seen at an injection time before the sand/clay interface is highlighted, indicating that the HFE is following the sand layering before it reaches the sand/clay interface. These reflections persist throughout the injection, indicating that the HFE thickness remains greater near the injection, which is confirmed in the post-injection cores. Farther away from the source, the HFE thickness is less, and the reflection from the top of the HFE is much closer in time to the sand/clay interface (Figures 12 through 15). Because the HFE saturation becomes greater with depth due to its density and gravity-capillary equilibrium, the sand/clay interface has a much greater permittivity contrast than the gradual or non-distinct top of the HFE. As a result, the top interface reflection is not as distinct in the GPR data. 
A steel rod was placed at the sand/clay interface at $14 \mathrm{~N}$ and can be seen as a parabolic reflection in the pre-injection images for $10 \mathrm{E}$ and $11 \mathrm{~W}$ (Figures 7 and 8). At later injection times, the reflection from the steel rod cannot be distinguished from the HFE highlighted sand/clay interface. The reflection from the steel rod is also seen in the $10 \mathrm{~N}$ and $04 \mathrm{~N}$ pre-injection images at approximately $11 \mathrm{~ns}$ (Figures $10 \mathrm{a}$ and 11a) because of the three-dimensional nature of the reflection. GPR waves transmitted from the antenna emanate in the shape of a cone; thus, the antenna detects reflected energy that is not directly below the antenna (Lucius and Powers, 1997), creating a parabolic nature in the reflection from the steel rod in the $2 \mathrm{D}$ images. The shortest reflection time, the top of the parabola, occurs where the antenna is directly over the rod, while energy reflected from the rod in the second and/or third dimension arrives later due to the greater travel distance of the GPR wave. This three-dimensional (3D) nature of GPR data is important for proper interpretation of 2D GPR images.

\section{Core Data}

Mass analyses of HFE saturation were completed on all of the core tubes, but error involved in measuring the exact tube volume, along with the loss of HFE during the cutting process, was large enough that the resulting saturation values were only qualitative. The mass analyses agreed with the visual observations of the amount and location of red color in the core tubes.

Visual and mass analysis data showed that HFE saturation increased with increasing depth in individual cores and total HFE thickness increased closer to the injection source. Distinct changes in HFE saturation between layers could be seen on occasion as an abrupt color change. The most notable of these abrupt color changes occurred in cores $10 \mathrm{~N}$ $0 \mathrm{EW}$ and $0 \mathrm{NS} 5 \mathrm{E}$. In $10 \mathrm{~N} 0 \mathrm{EW}$ there was a graduated color of dark to medium red for 0 $7.62 \mathrm{~cm}$ above the clay followed by an abrupt contact to lighter red from $7.62-13.02 \mathrm{~cm}$ above the clay. This contact corresponds well with the reflection seen at $10 \mathrm{~N}$ in Figure 10 at a time of approximately $7 \mathrm{~ns}$. In $0 \mathrm{NS} 5 \mathrm{E}$, the HFE occurred in a gradually decreasing red color from $0-5.40 \mathrm{~cm}$ above the clay followed by an interval of no red color from 5.40-7.62 $\mathrm{cm}$ above the clay. This was then followed by a thin red stringer in only one side of the core from 7.62-7.94 cm above the clay. This contact corresponds well with the reflection seen at $7 \mathrm{~ns}$ in $04 \mathrm{~N}$ on the east side of the tank (Figure 11). This same reflection was also seen in the $2 \mathrm{D}$ GPR image at $01 \mathrm{~N}$, but was not readily apparent in any traces south of $0 \mathrm{NS}$. 


\section{GPR Modeling}

\section{Background}

Ground penetrating radar data are modeled using a software package that computes the GPR response by calculating the transmitted and reflected waves as the pulse is propagated through a geologic model of flat, horizontal layers of specified thickness and associated electromagnetic properties (complex dielectric permittivity, electrical conductivity, and complex magnetic permeability). The user adjusts the geologic model to obtain a GPR response that is most similar to the field-measured response. Solutions are not unique, but may be constrained by the user based on prior knowledge of the medium and/or subsurface geometry. The one-dimensional (1D) full-waveform GPR modeling software used in this research is a module of GRORADAR ${ }^{\mathrm{TM}}$ version 8.99 (Olhoeft, 1998), which is based upon GPRMODV2 by Powers and Olhoeft (1995). Onedimensional GPR modeling was used to quantitatively determine the change in dielectric permittivity of the initially water-saturated sand as HFE filled the pore spaces.

Quantitative permittivity values from the 1D GPR modeling were also used in a 2D GPR modeling program (Powers, 1997). The 2D GPR modeling was used qualitatively to confirm the absence and/or presence of multidimensional influences. Powers (1995) provides detailed descriptions of the theory and formulation of both the 1D and 2D GPR modeling codes.

\section{One-dimensional GPR model parameters}

GPR modeling input parameters include the parameters associated with the GPR antenna, geologic geometry and associated electromagnetic properties. The character of the energy reflected from the steel sheet was used to determine the coupling ratio of the GPR antenna with the saturated sand. The coupling ratio determines the reduction in the radar wave frequency due to near-field affects around the antenna (Lucius and Powers, 1997). The GPR antenna was rated for $1.5 \mathrm{GHz}$, but the coupling ratio of 1.95 indicates an actual frequency of 769 megahertz $(\mathrm{MHz})$ within the sand. The shape of the reflection also indicated the radar wave was in the form of a Ricker wavelet. The initial Ricker wavelet and the Ricker wavelet with a coupling ratio of 1.95 are shown in Figure 16. The slight leader (flat portion) on this wavelet at early times has been found to produce the best GPR modeling results (Powers, M.H., 2003, oral communication). Antenna wavelet forms and their affects on GPR modeling are discussed briefly in Sneddon and others (2002). Field traces were adjusted for the firing time of the antenna, which was generally at $2.43 \mathrm{~ns}$ into a total measurement window of $20 \mathrm{~ns}$. This time was slightly later on a few profiles (up to $2.65 \mathrm{~ns}$ ) when the antenna was used from 1-2 hours after the equipment was turned on, indicating a longer warm up period was required. 


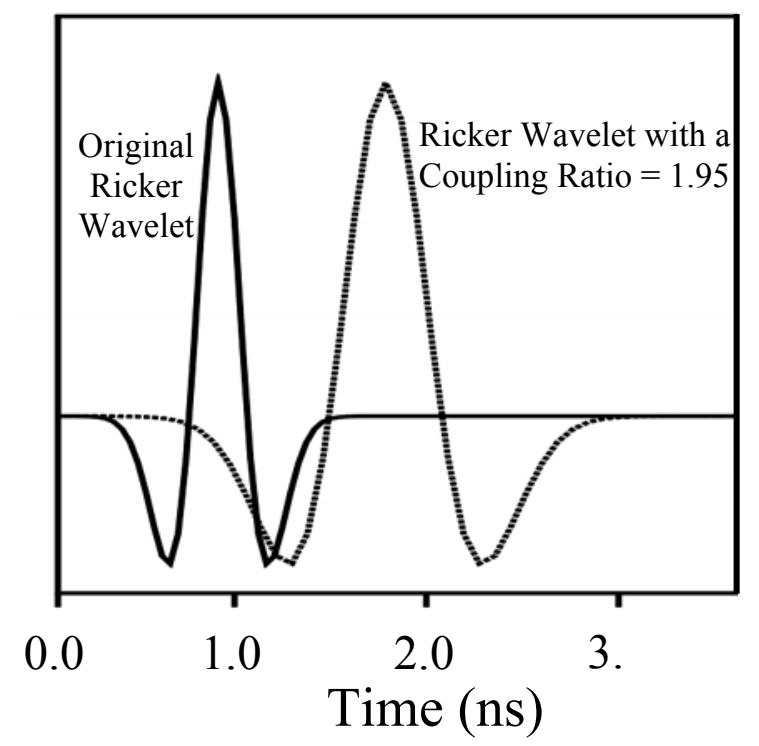

Figure 16: Original Ricker wavelet and Ricker wavelet with a 1.95 coupling ratio, which is used in the 1D GPR modeling 
Materials in the tank included quartz sand, pottery clay, water, dyed HFE, air, Plexiglas and steel. Water, dyed HFE, air, and quartz sand are always present as mixtures. None of these materials are magnetic, so the electromagnetic properties of concern are complex dielectric permittivity and electrical conductivity. The pre-injection permittivities of Plexiglas, air/water/sand, water/sand, and clay used in all the GPR modeling were 2.5, 10.0, 23.0, and 28.0 respectively and are shown in Figures 17 and 18. The permittivity of Plexiglas was measured to be 2.74 using a parallel-plate capacitor and ASTM method D 150-98 (American Society of Testing and Materials, 2002) at a frequency of $1 \mathrm{MHz}$. However, the measurement showed Plexiglas is somewhat frequency dependent with a decreasing value as the frequency increases. The parallel-plate capacitor could not measure permittivity at a frequency above $1 \mathrm{MHz}$, so a value of 2.5 was assumed. The permittivity of dyed HFE and distilled water were measured to be 6.85 and 80 , respectively, at $1 \mathrm{MHz}$ and $20^{\circ} \mathrm{C}$ in a liquid parallel-plate capacitor using ASTM method D 150-98. These values were assumed to remain constant up to $1 \mathrm{GHz}$, since no frequency dependence was observed in the 0.1-1.0 $\mathrm{MHz}$ range

The porosity of the water-saturated sand was measured from cores, and ranged from $36 \%$ to $38 \%$. The pore structure in the top of the water-saturated sand cores collapsed upon cutting as the material liquefied in response to vibration. The pore structure did not collapse in zones with high DNAPL saturation because the DNAPL was relatively immobile, and the porosity could be accurately measured. Using a permittivity of water and sand at 80 and 4.5, respectively, and the BHS curve (Sneddon and others, 2002), the calculated permittivity for a $37 \%$ porosity sand is 23 . This procedure was confirmed for air/water/sand mixtures by direct measurements (Johnson and Poeter, 2003b). The porosity of the clay was measured by air drying to be $41 \%$. Assuming a quartz sand matrix, this porosity yields a permittivity value of 25.7 , but the actual permittivity of the clay particles was unknown. For the air/water/sand layer, since the permittivity of air is one, a small amount of air dramatically decreases permittivity. Using the procedure discussed in Johnson and Poeter (2003b), the permittivity of a $37 \%$ porosity sand with $50 \%$ air saturation is 9.5 . In addition, total direct contact between the Plexiglas and the wet sand was not possible, allowing for a small (less than a few $\mathrm{mm}$ ) gap of low permittivity air just below the Plexiglas. The permittivities of 10 and 28 used in the GPR modeling for the air/water/sand layer (unsaturated zone) and the clay, respectively, were determined via calibration. The calibration used the reasonable starting permittivity values listed above with a known thickness for the clay and a reasonable thickness for the unsaturated sand. The permittivity values were then adjusted to match the reflection of the steel sheet, which occurs at a known depth. The pre-injection permittivity value for the water-saturated sand was 23.0 in the center of the tank, but had to be adjusted slightly (down to 21.5) at the edges of the tank to produce a match of the 1D GPR model to the reflections from the steel sheet. This can be attributed to slight interferences in the GPR wave near the edges of the tank, rather than porosity variation. 
a)

10N Pre-injection $\quad \varepsilon \quad$ Depth $(\mathrm{cm})$

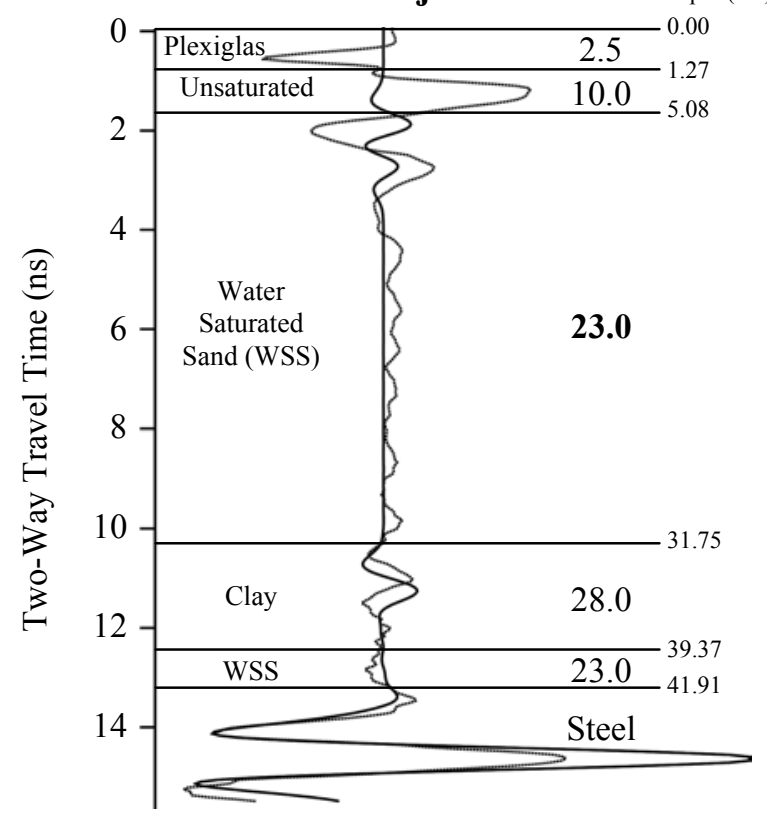

c)

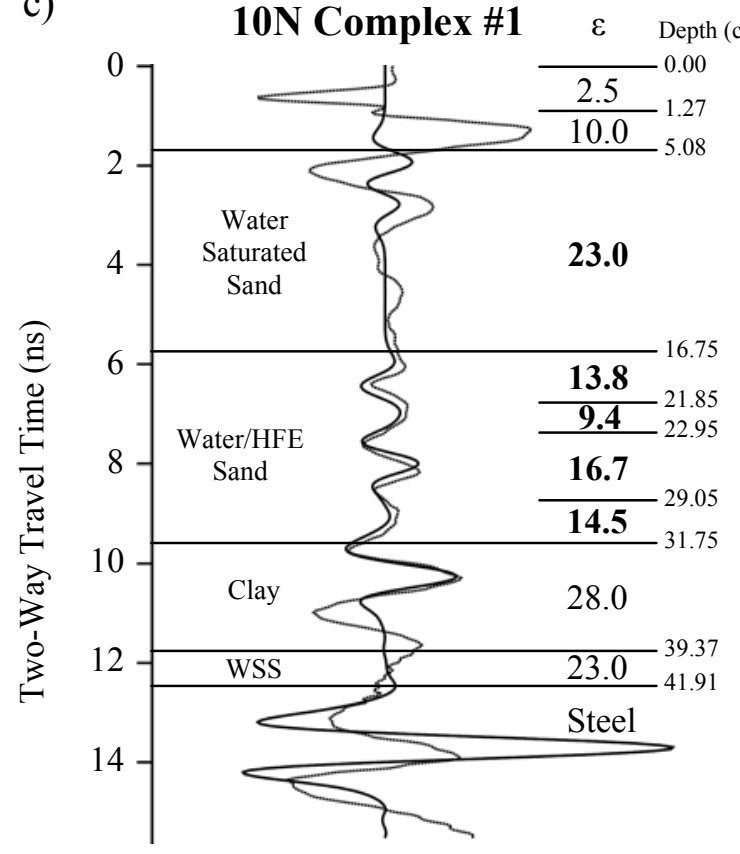

b)

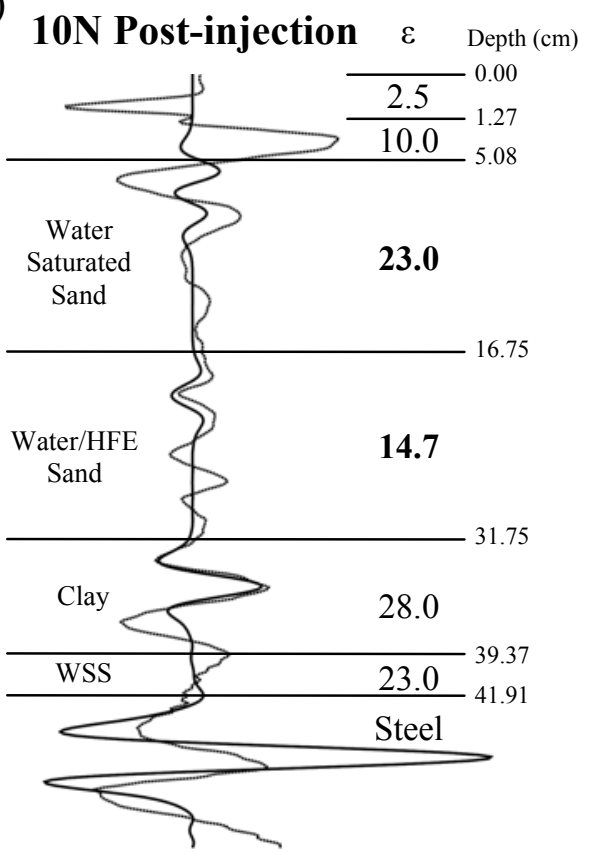

d)

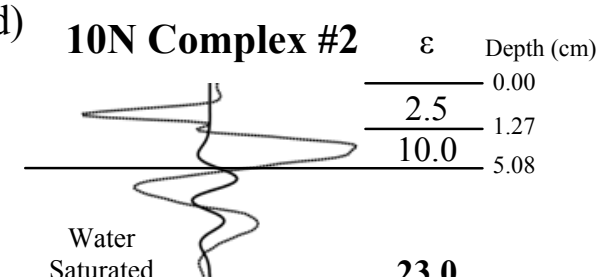

Figure 17: GPR traces for sand tank at 10N 0EW, dashed line is measured trace and solid line is modeled trace: a) pre-injection; b) post-injection; c) complex match \#1; and d) complex match \#2. 
a)

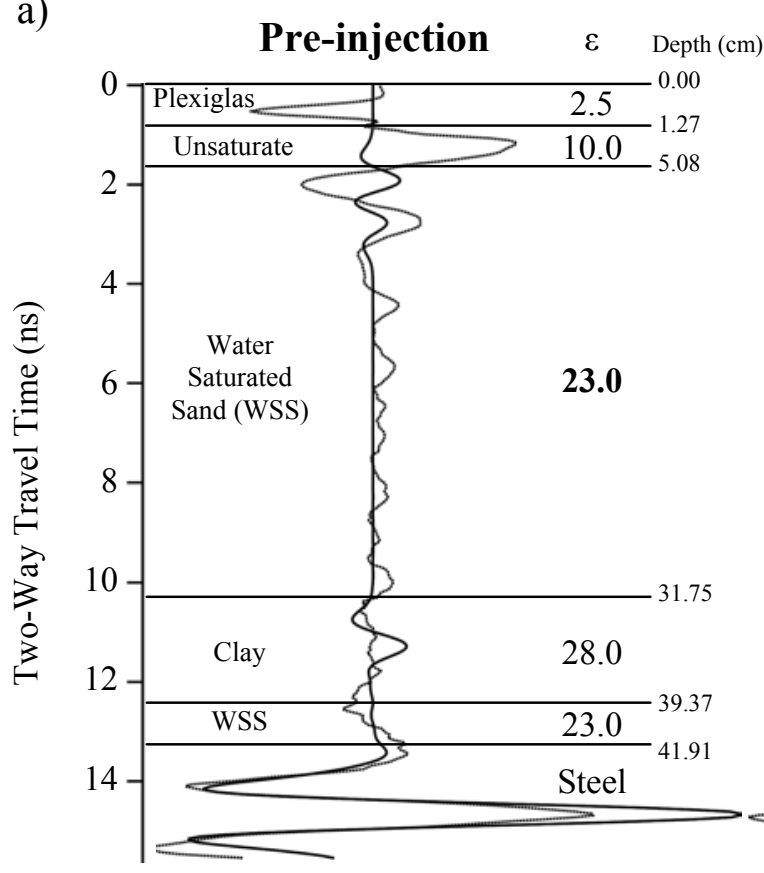

c)

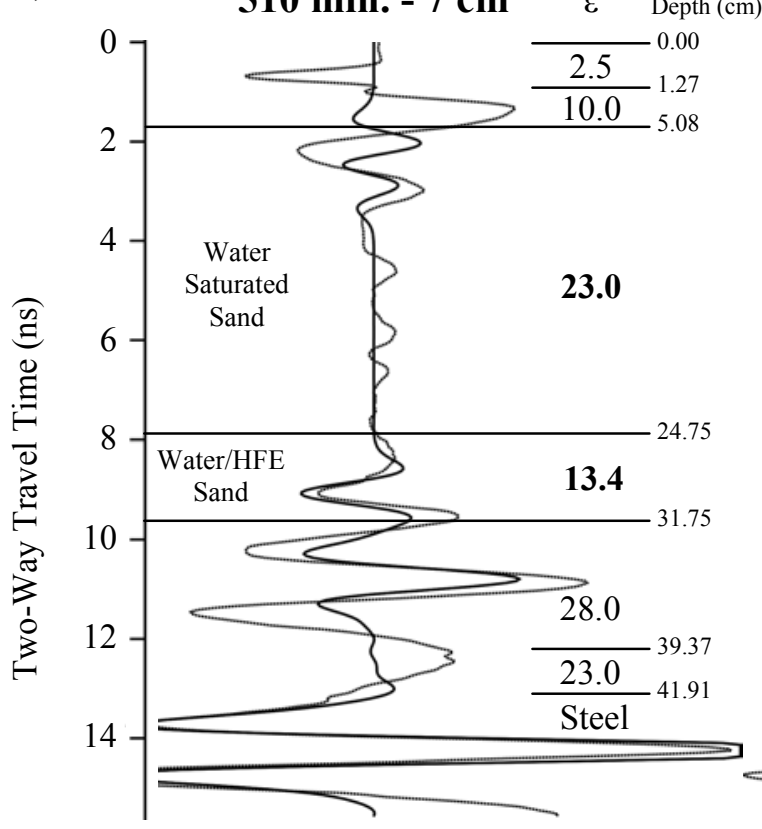

b)

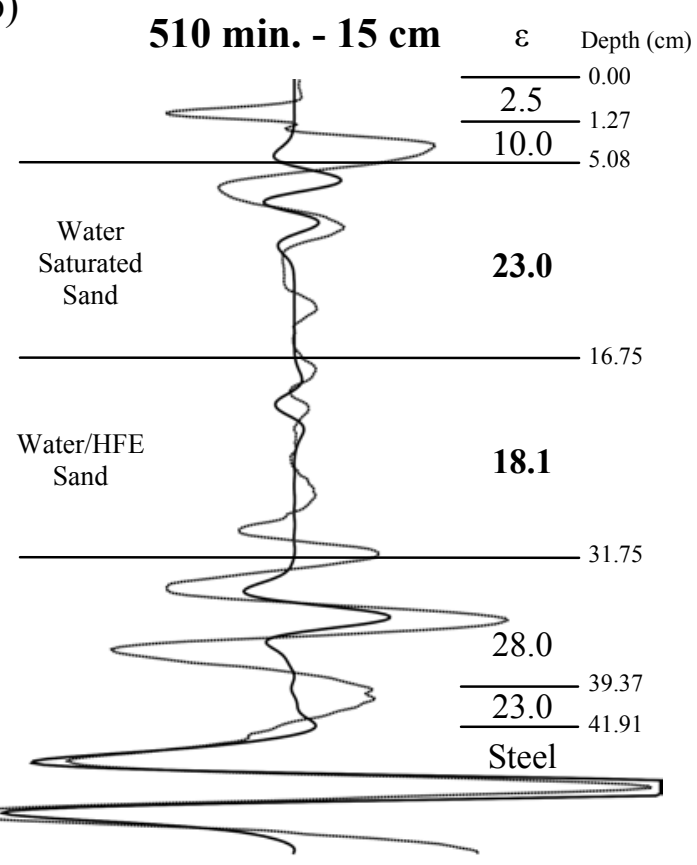

d)

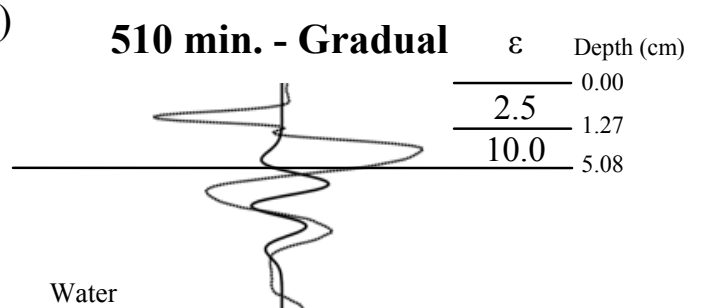

Figure 18: GPR traces for sand tank at $02 \mathrm{~S} 0 \mathrm{EW}$, dashed line is measured trace and solid line is modeled trace: a) pre-injection; b) 510 minutes assuming $15 \mathrm{~cm} \mathrm{HFE}$ thickness; c) 510 minutes assuming $7 \mathrm{~cm}$ HFE thickness; and d) 510 minutes assuming increasing HFE saturation with depth. 
The electrical conductivity of the water-saturated sand was measured to be 10 milliSiemens/meter $(\mathrm{mS} / \mathrm{m})$ using a hand held conductivity meter. Steel is infinitely conductive and air, dyed HFE, and Plexiglas are effectively non-conductive $(0 \mathrm{mS} / \mathrm{m})$. Using the gain function from a 1D GPR model at the center of the sand tank, a $200 \mathrm{mS} / \mathrm{m}$ electrical conductivity value for the clay provided the best match for the attenuated reflection amplitude of the steel sheet where the clay was the thickest. Since air and dyed HFE are not conductive, any sand that was not water-saturated was given a constant conductivity of $5 \mathrm{mS} / \mathrm{m}$. Electrical conductivity values were the same in all 1D GPR models for Plexiglas, air/water/sand, water-saturated sand, water/HFE/sand, clay, and steel at $0,5,10,5,200$, and $10^{10}(\mathrm{mS} / \mathrm{m})$, respectively.

\section{One-dimensional GPR modeling procedure}

The initial procedure for 1D modeling of GPR data from the sand tank is similar to the procedures discussed in Sneddon and others (2002). In both cases, pre-injection layering within the sand is subtle because reflections of radar waves are controlled by permittivity changes due to slight variations in porosity, which is assumed to also reflect slight changes in the intrinsic permeability of the sand. Inflow of DNAPL highlights higher permeability layers because the permittivity of DNAPL is much lower than water, creating a larger permittivity contrast between zones with and without DNAPL.

The challenge in matching a measured 1D GPR trace with a 1D GPR model is in choosing the layer thickness and permittivity. For the Borden data, Sneddon and others (2002) used a "top down" approach where the depths of layers highlighted by DNAPL were used to identify the original pre-injection layering. This procedure relies partially upon the amplitude of the reflection of the highlighted DNAPL because the two variables, depth and permittivity, are both unknown. The amplitude gain function for the GPR data is unknown, but Sneddon and others (2002) fixed the gain function for all of the GPR modeling for consistency. This approach was attempted for the sand tank to match the HFE highlighted layering, but the results were not unique (Figures $17 \mathrm{c}$ and 17d). Changes in HFE saturation, modeled as permittivity changes, were required to produce the associated reflections, but different distributions of HFE saturation produced similar results. This non-uniqueness lead to a new procedure of using a broad DNAPL zone with a bottom at the sand/clay interface and a fixed top depth at, or slightly greater than, the first highlighted horizon.

Use of one DNAPL zone relies on a matching of arrival times and fixed depths, eliminating matching to reflection amplitudes, and improving the reliability of the model results. The DNAPL saturation for the entire zone is calculated using the BHS curve (Sneddon and others, 2002) based on the permittivity relative to pre-injection conditions. Using the DNAPL saturation and the thickness of the zone, the volume of DNAPL in a square centimeter column can be calculated. The top of the HFE zone was held constant through time while the permittivity of the whole zone was adjusted in order to match the 
reflection from the sand/clay interface and the steel sheet. Since the radar wave travels faster through a HFE/water/sand mixture than a water-saturated sand, the reflections from the sand/clay interface and the steel sheet at later injection times occur at an earlier radar wave travel time, requiring a reduced permittivity for the HFE/water/sand mixture (Figures 17a, 17b, 18a, and 18b). As shown in Figure 18, the exact selection of the top of the DNAPL zone is irrelevant because a thicker zone requires a higher permittivity of the DNAPL zone to create a correct match, while a thinner zone requires a lower permittivity. The different permittivities produce a consistent change in the DNAPL saturations, which produce the same total DNAPL volume, within the error of the matching procedure. The matching error refers to the range of permittivity values for the HFE/water/sand mixture, which are used to calculate the total DNAPL volume, that still produce a good GPR model fit to the steel sheet reflection. For the $15 \mathrm{~cm} \mathrm{HFE} \mathrm{zone} \mathrm{in}$ Figure $18 \mathrm{~b}$, the DNAPL volume in a square centimeter column is $0.999 \mathrm{~cm}^{3}$ with a range of 0.955 to $1.087 \mathrm{~cm}^{3}$ based on the matching error. For the $7 \mathrm{~cm}$ HFE zone in Figure $18 \mathrm{c}$, the DNAPL volume is $1.020 \mathrm{~cm}^{3}$ with a range of 0.994 to $1.046 \mathrm{~cm}^{3}$. For the gradual match in Figure 18d, where HFE saturation increases with depth, the DNAPL volume is $1.044 \mathrm{~cm}^{3}$ with a range of 0.994 to $1.046 \mathrm{~cm}^{3}$. This example shows that the DNAPL volumes determined with different HFE zone representations are all within the range of the original values for a $15 \mathrm{~cm}$ thickness.

The HFE volumes within a square centimeter column at 200 minutes are shown in Figure 19 and the final post-injection volumes are shown in Figure 20. In most of the tank, a match to the steel sheet reflection also produced a match to the sand/clay interface (Figures 17 and 18). However, in the southeast corner of the tank, the reflection from the sand/clay interface occurs at an earlier radar wave travel time when the GPR model is matched to the reflection from the steel sheet (Figure 21). In the southeast corner of the tank, the steel sheet reflection is distorted, possibly by reflections from the walls of the tank, so the 1D GPR model is matched to the first arrival time of the steel sheet reflection. Contoured post-injection HFE volumes based on a sand/clay interface match are shown in Figure 22, where, based on core data, the increase in DNAPL volumes in the southeast corner is unrealistic.

The bias in the southeast corner of the tank in calculating HFE volumes from the sand/clay interface are attributed to a three-dimensional interference in the reflected radar waves. In this area, 3D radar wave reflections from the intersection of the two sloped sand/clay interfaces with HFE in the sand are amplified and then received by the antenna. This interference only occurs at locations where the time of arrival of reflections from the sloped walls interferes with the time of arrival of the sand/clay interface directly below the antenna. Using a 1D GPR model to match traces generated by a 2D GPR model with an interference reflector reproduces this incorrect match. In this case, a permittivity of 17.1 for the water/HFE/sand unit in a 2D GPR model is calibrated correctly using the steel sheet as a reference, but a permittivity of 8.6 is incorrectly determined using the 


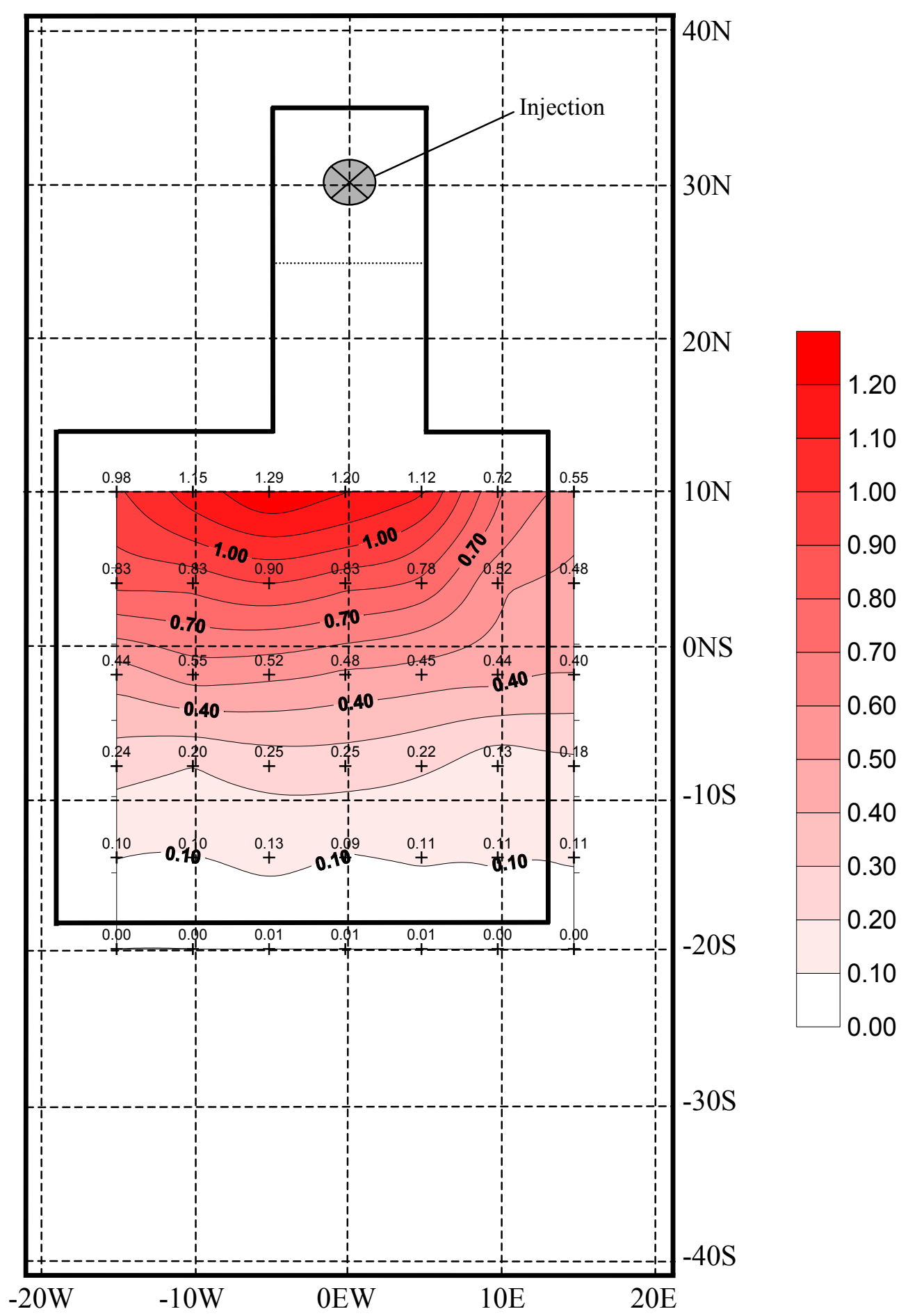

Figure 19: HFE volume $\left(\mathrm{cm}^{3}\right)$ within one square centimeter columns at 200 minutes into injection. Crosses indicate data locations. Distances are in centimeters. 


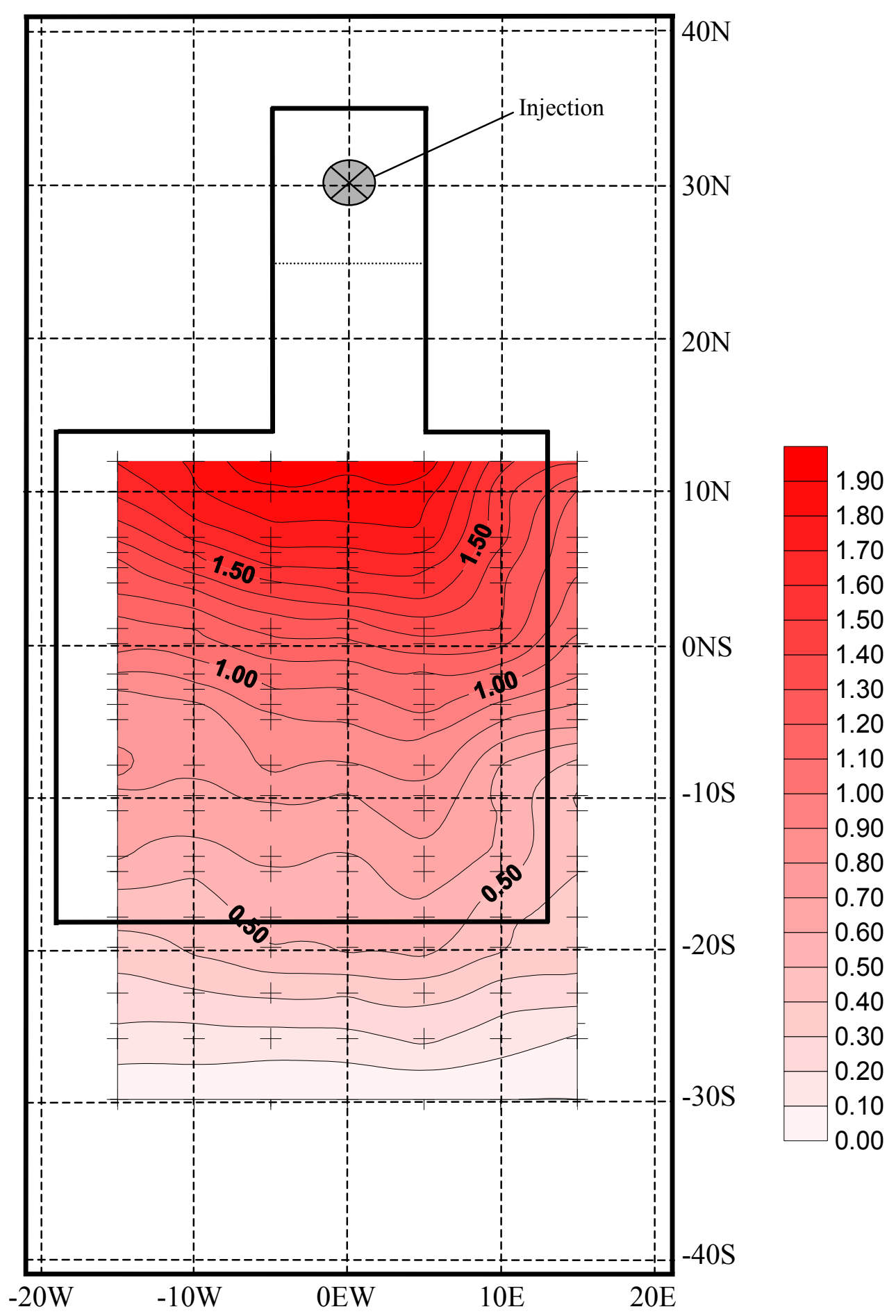

Figure 20: HFE volume $\left(\mathrm{cm}^{3}\right)$ within one square centimeter columns at post-injection with a match to the steel sheet. Crosses indicate data locations. Distances are in centimeters. 
a)

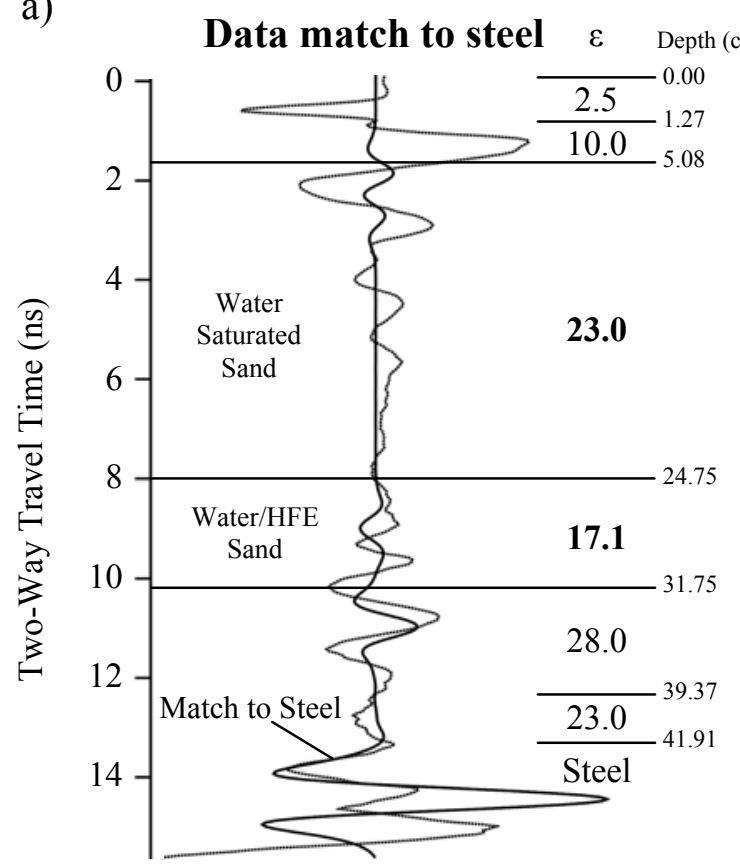

c)

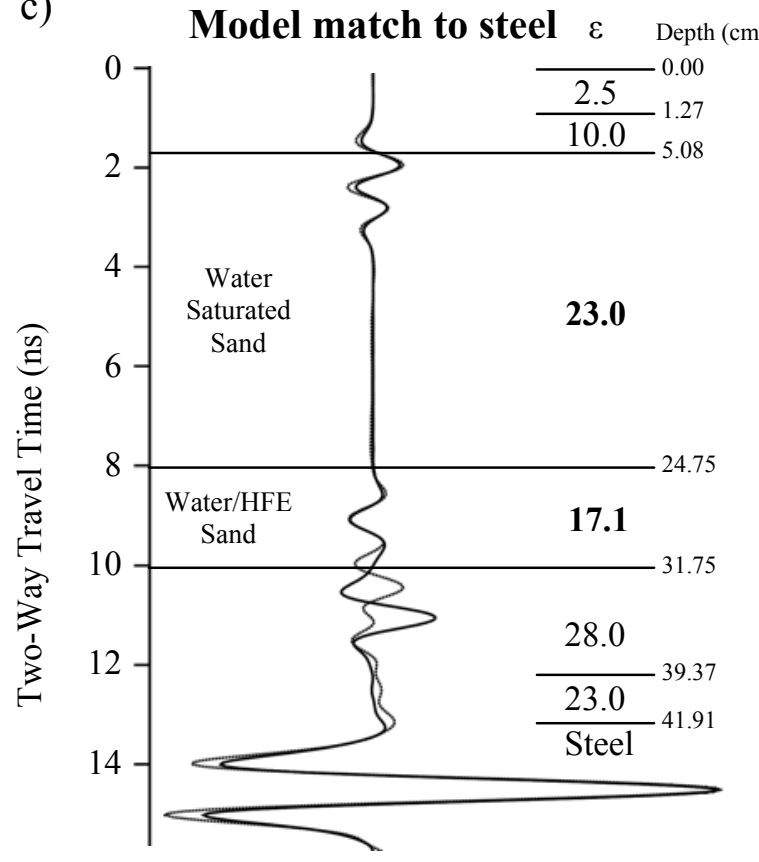

b)

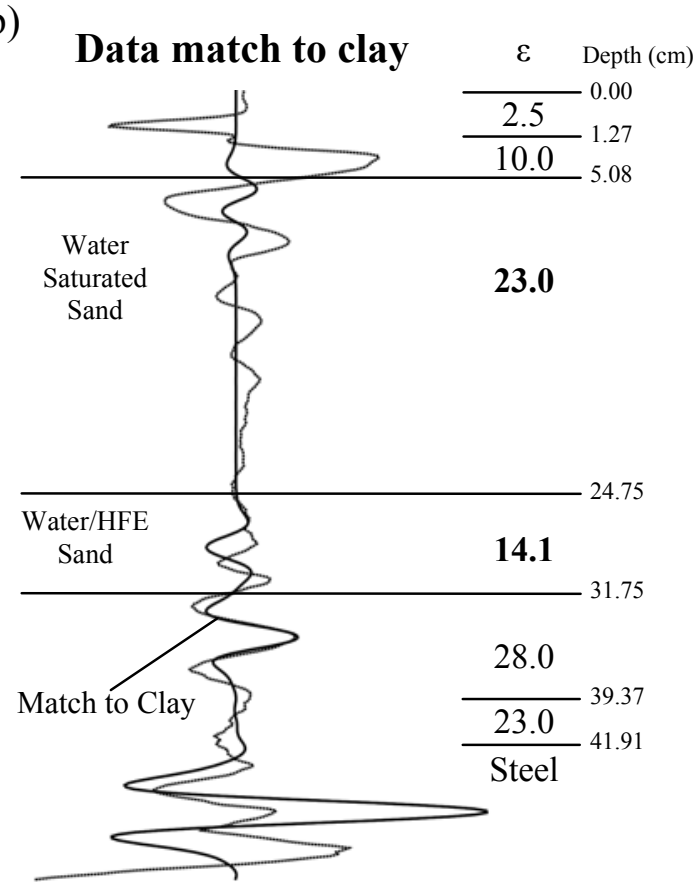

d)

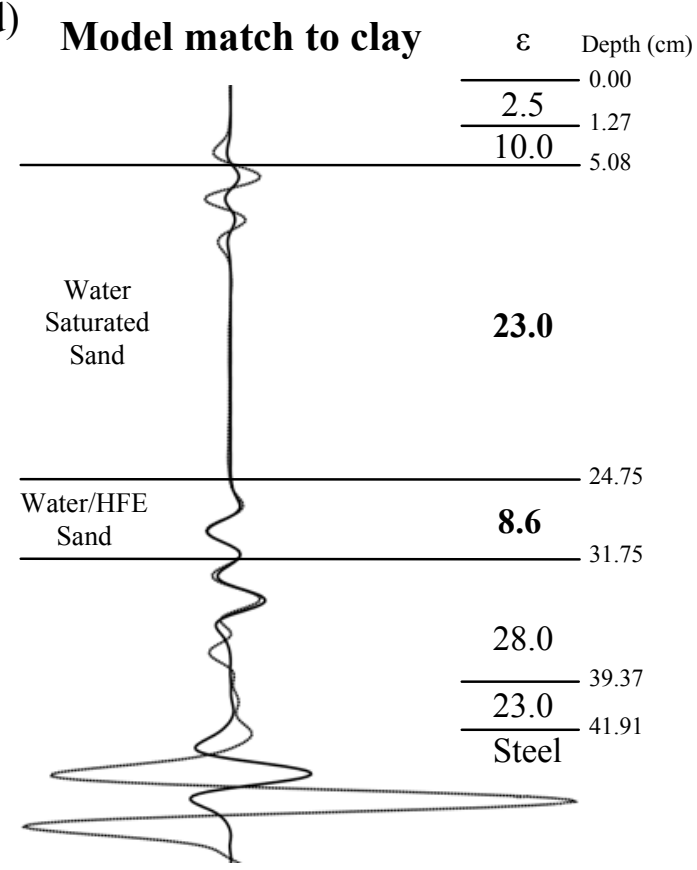

Figure 21: Post-injection GPR traces for sand tank at 18S 5E, dashed line is measured trace in a $\&$ b and 2D model trace in c $\& d$. Solid line is 1D model trace: a) match to steel with measured data; b) match to clay with measured data; c) match to steel with 2D model; and d) match to clay with 2D model. 


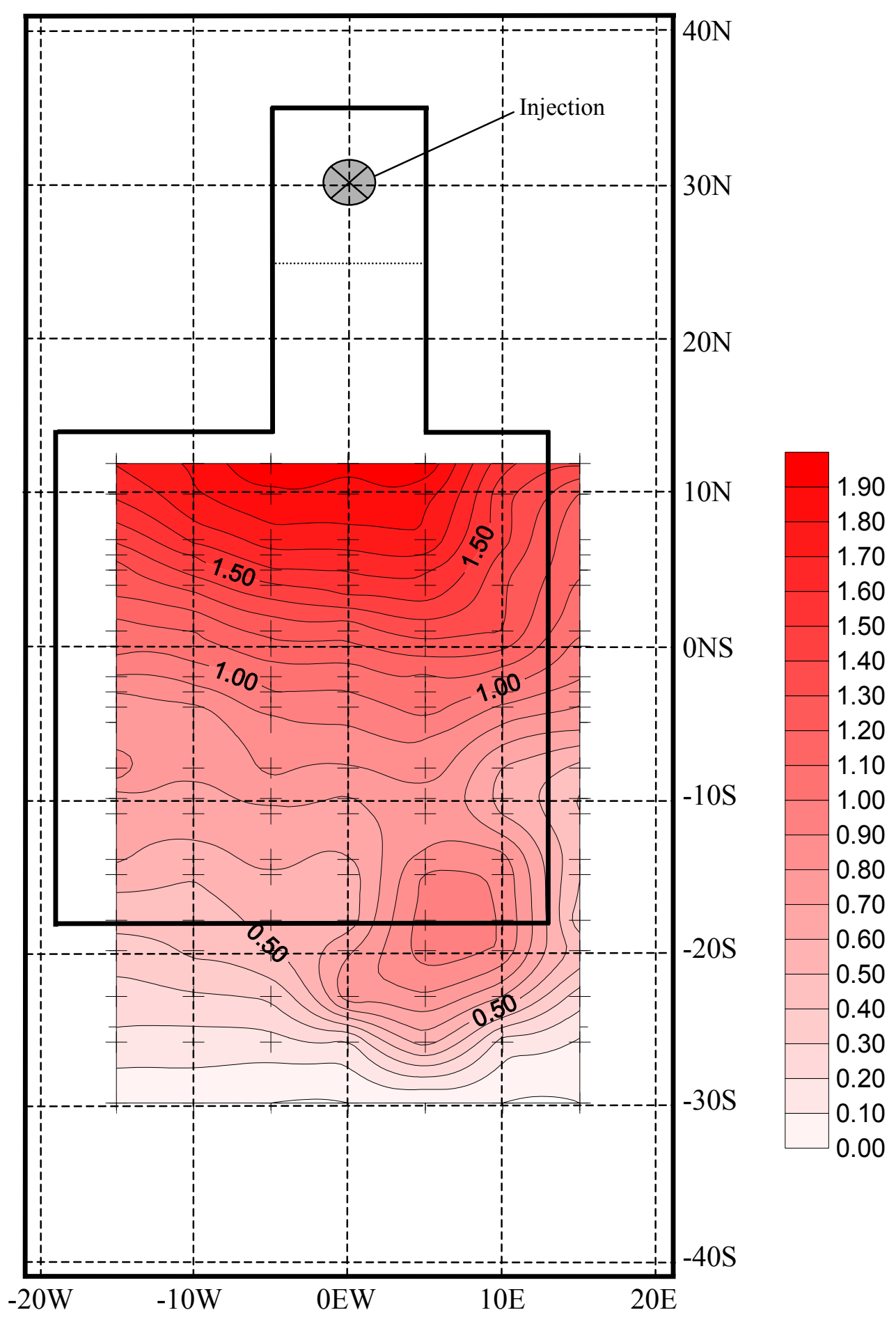

Figure 22: HFE volume $\left(\mathrm{cm}^{3}\right)$ within one square centimeter columns at post-injection with a match to the sand/clay interface. Crosses indicate data locations. Distances are in centimeters. 
sand/clay interface (Figures 21c and 21d). This bias is discussed in the 2D GPR modeling section below.

\section{Two-dimensional GPR modeling of sand tank}

The 2D GPR model used in this research is described in Powers $(1995,1997)$. While the 1D GPR model considers only reflections directly below the GPR antenna, the 2D GPR model considers specular reflections in the second dimension. Energy from the GPR antenna is transmitted in a cone shaped pattern below the antenna (Lucius and Powers, 1997); consequently, energy from reflections that are not directly below the antenna can be received.

All of the 2D GPR models use the same layering and permittivity values presented for the 1D GPR models. With the inflow of HFE, the saturated sand unit is reduced in thickness and a unit with water/HFE/sand is added. The only difference in the 2D GPR models is the representation of the actual shape of the sand/clay interface rather than representing it as a horizontal plane. At this time, the 2D GPR models cannot be as precisely compared to the actual GPR data as the 1D GPR models because the program does not allow for interactive user changes in parameters with detailed output comparisons like the 1D GPR modeling program. However, the 2D GPR model output can be compared qualitatively with measured data to evaluate whether $2 \mathrm{D}$ influences must be considered. A comparison of the GPR data and the 2D GPR model at preinjection, 102 minutes, and post-injection for east-west trace 02S is shown in Figure 23 along with the geometry used in the 2D GPR model. Inflow of HFE is modeled as a 7$\mathrm{cm}$ layer at 102 minutes and post-injection, with a permittivity of 21 at 102 minutes and 13.4 at post-injection. These permittivity values and thicknesses were originally determined from the 1D GPR modeling. The 2D GPR models produce a good qualitative match to the GPR data, which shows that two-dimensional influences, such as reflections from the angled clay walls, are not a concern within the tank. Similarly, pre-injection and post-injection GPR data and 2D GPR models for north-south trace 10E are shown in Figures 24 and 25. In Figures 24 and 25, the steel rod was not included in the GPR model in order to highlight the sand/clay interface. As discussed in the 1D GPR modeling section, the sand/clay interface at pre-injection shows a slightly greater reflection in the GPR modeling than in the laboratory data (Figures 23a, 23b, 24a and 24b). As shown by Figure 25, the model requires thicker HFE close to the injection to produce the pull-up in the steel sheet and the early reflection time for the top of the HFE. The 2D model simulates the attenuated signal from the steel sheet where the clay is thicker, especially in the north end of the tank (Figure 25). Overall, the pattern of the 2D GPR model is similar to the data, indicating that the model is representative of the sand tank. Within much of the tank, 2D influences are minimal; thus, use of 1D GPR modeling for estimation of the HFE saturation is appropriate. However, 3D influences near the southeast corner of the tank violate the 1D assumptions and produce incorrect 

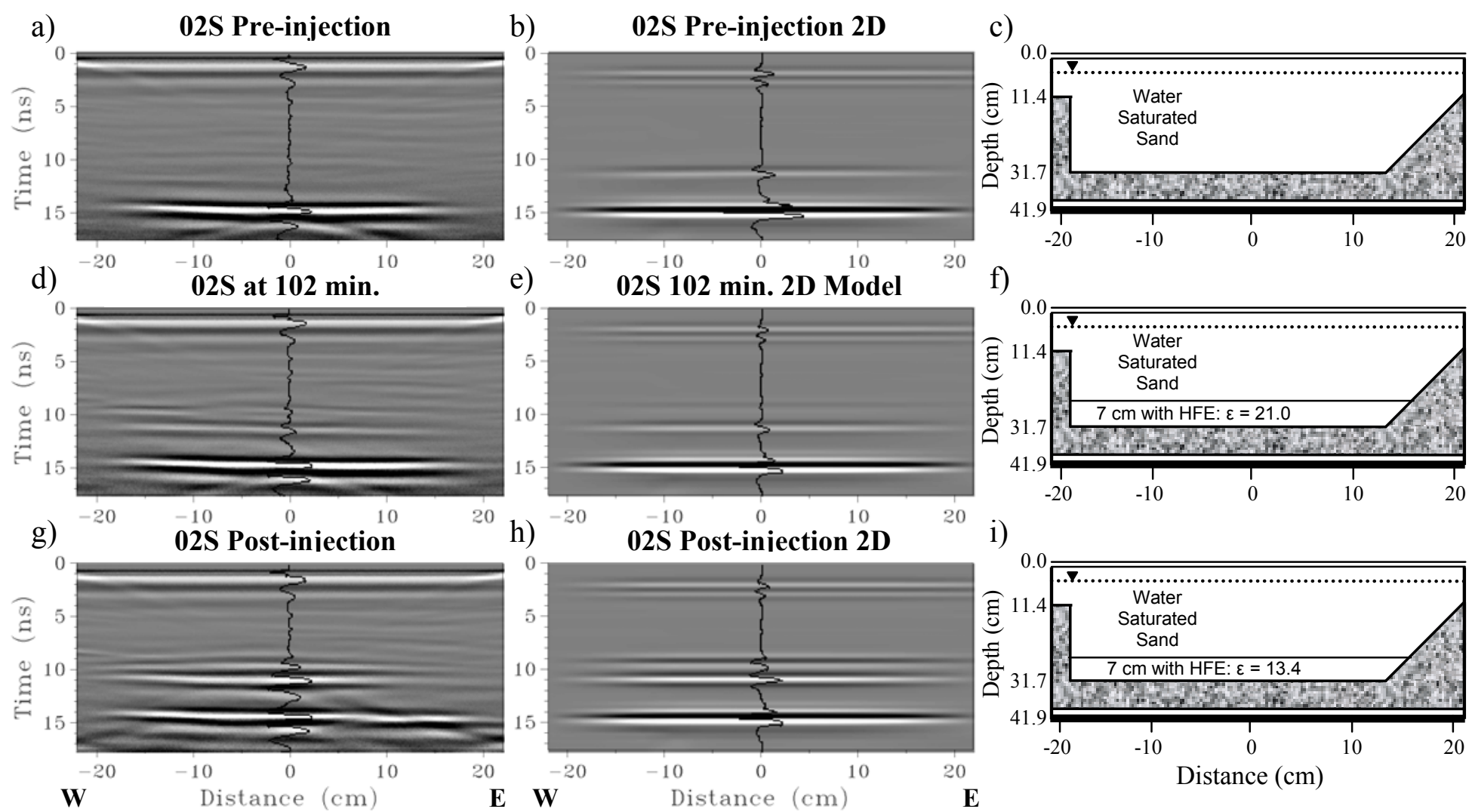

Figure 23: GPR images along 02S, looking north. Wiggle-trace displays are at the center of the tank: a) pre-injection data; b) pre-injection model; c) pre-injection geometry; d) data at 102 min.; e) model at 102 min.; f) geometry at 102 min.; g) post-injection data; h) post-injection model; and i) post-injection geometry. 
a)

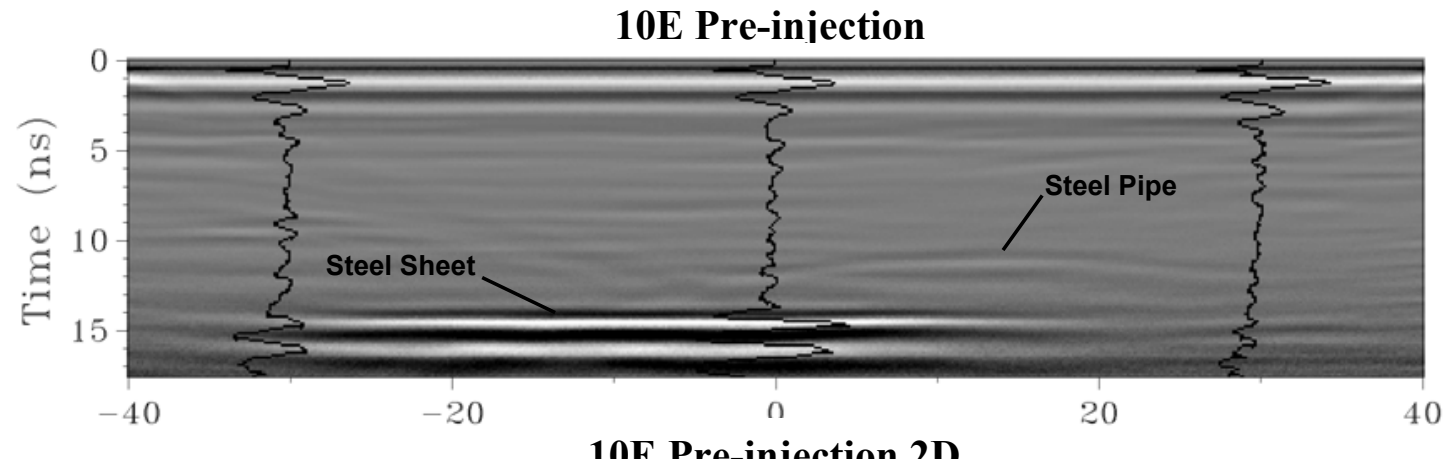

b)

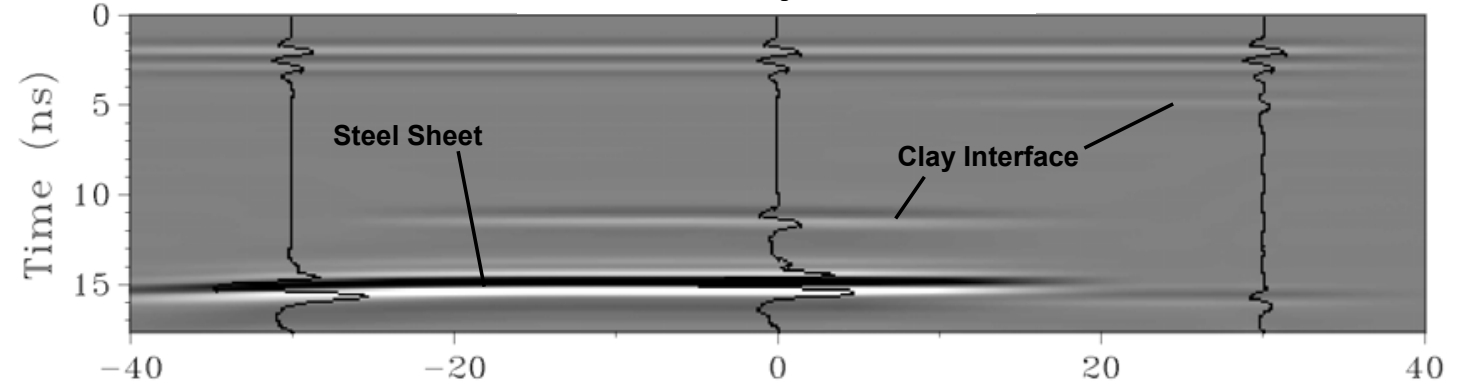

c)

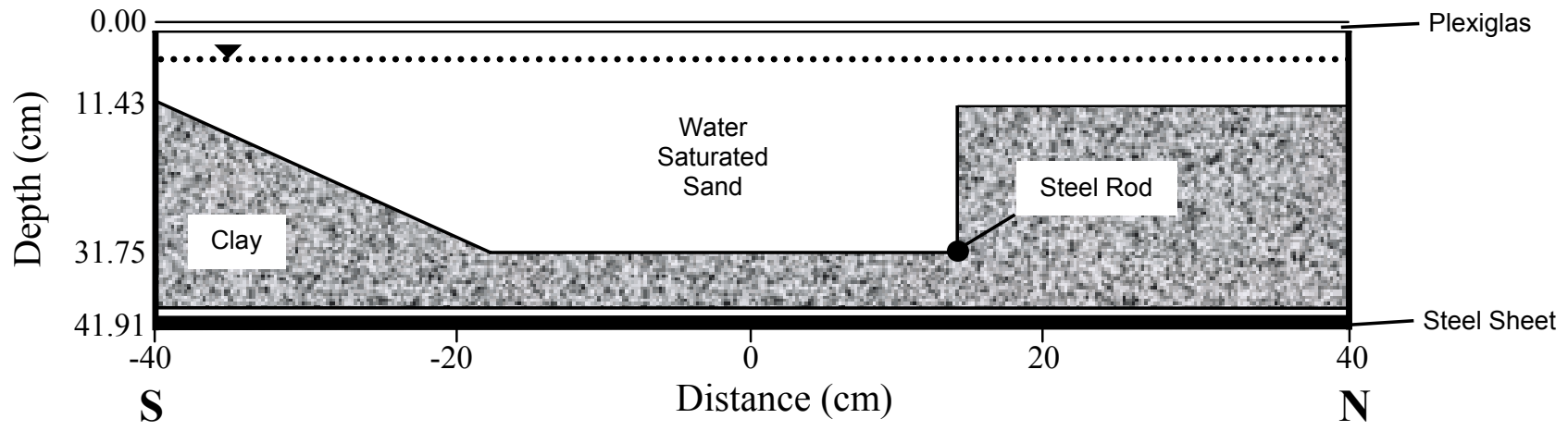

Figure 24: Images along 10E at pre-injection, looking west. Wiggle-trace displays are at $-30,0$, and $30 \mathrm{~cm}$ : a) GPR data; b) 2D model; and c) geometry. 
a)

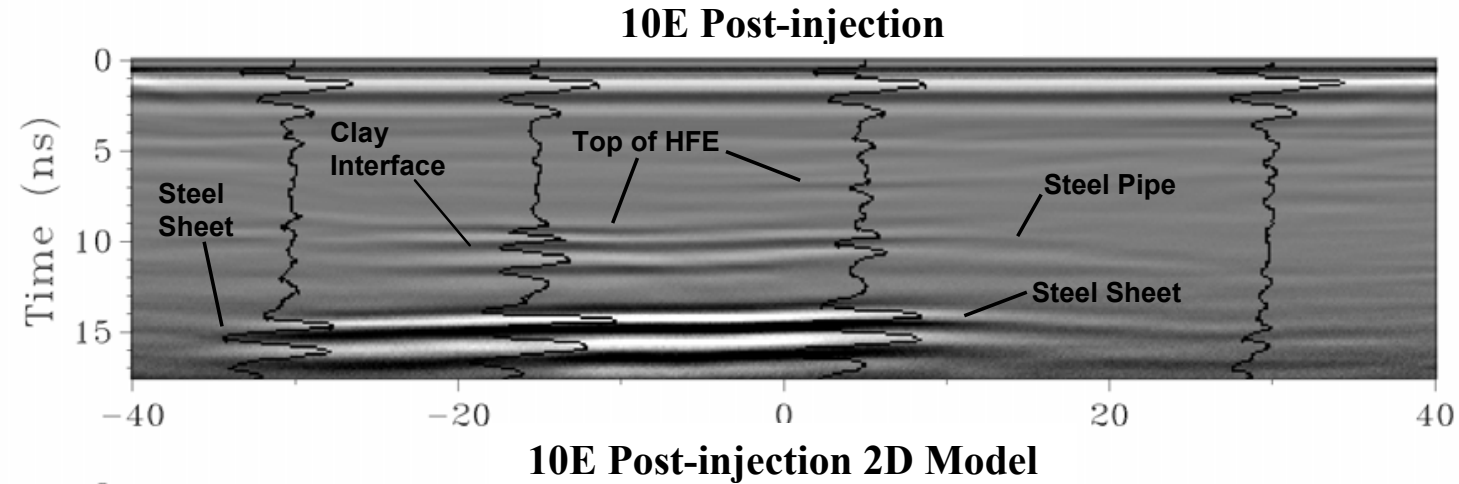

b)

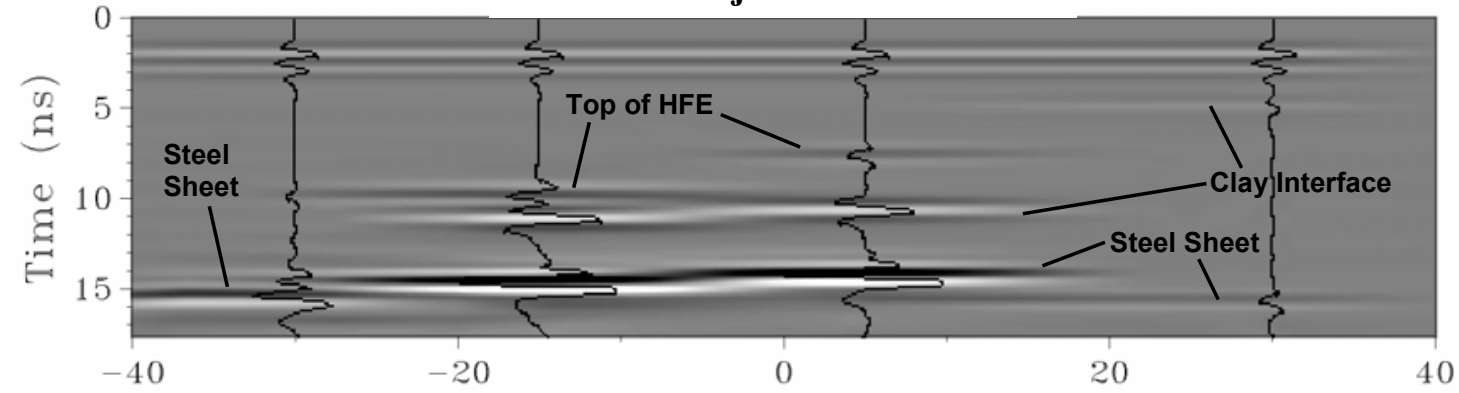

c)

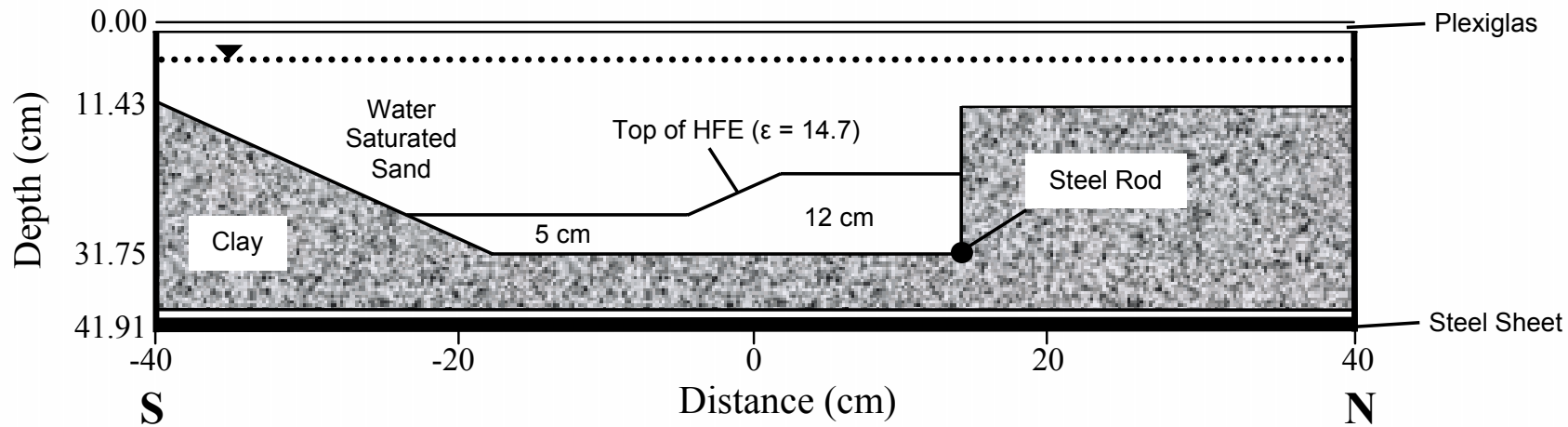

Figure 25: Images along $10 \mathrm{E}$ at post-injection, looking west. Wiggle-trace displays are at -30 , $-15,5$, and $30 \mathrm{~cm}$.: a) GPR data; b) 2D model; and c) model geometry. 
interpretations when matching to the sand/clay interface, thus requiring multidimensional GPR modeling to clarify the interpretation.

The 3D influence in the southeast corner of the tank was reproduced in two dimensions using an added reflector along the sloped sand/clay interface on the east side of the tank (Figure 26). A three-dimensional GPR modeling program is not yet available, so this $3 \mathrm{D}$ influence is approximated in two dimensions. This reflector is positioned at a location to produce a similar response in time and space. The wiggle traces in Figure 26 are the 1D traces that were presented in Figures 21c and 21d to demonstrate the error associated with determining the permittivity of the water/HFE/sand unit when matching to the sand/clay interface. As shown in Figure 26, the permittivity of the HFE zone used in the 2D GPR model was 17.1, which is correctly matched in the 1D GPR model in Figure $21 \mathrm{c}$ by matching the steel sheet reflection. In Figure $21 \mathrm{~d}$, matching the 1D GPR model to the sand/clay interface yields the incorrect permittivity of 8.6 for the water/HFE/sand unit.

\section{Conclusions}

Collection of GPR data over a DNAPL injection zone efficiently produces a detailed image of the bulk DNAPL distribution in time and space. GPR data can be used to quantitatively determine the volume of DNAPL as indicated by interpretation of GPR response to a DNAPL injection (HFE) in a small sand tank. This was achieved using the two-way travel time of radar waves reflected from a steel sheet placed below the sand tank, where increasing DNAPL volumes are indicated by decreasing travel times. The known depth to the steel sheet allows for the calibration of the permittivity of the intervening material based on the arrival time of the steel sheet reflection. Although a quantitative determination of DNAPL saturation could not be established using the core data, the qualitative, visually estimated saturation of the cores were consistent with the GPR data. One-dimensional GPR modeling of the DNAPL layers within the tank was non-unique due to an absence of depth data and a reliance upon reflection amplitudes; thus, identification of varying DNAPL saturation with depth could not be achieved.

Two- and three-dimensional influences within the tank were minimal, except in the southeast corner of the tank, where the intersection of the sloping clay walls produced an amplified reflection of the DNAPL zone, as illustrated by 2D GPR modeling. This multidimensional nature of GPR data biased the results from 1D GPR modeling because the tank walls influenced the reflection from the sand/clay interface. This bias was identified with 1D GPR modeling that matched the steel sheet reflection, 2D modeling that confirmed multidimensional interferences, and visual core data. Zones of inconsistent DNAPL saturations interpreted from 1D GPR models should be examined for possible multidimensional interferences due to geometry. This research confirms that biased DNAPL saturations calculated from 1D GPR model calibration (Sneddon and 
a)

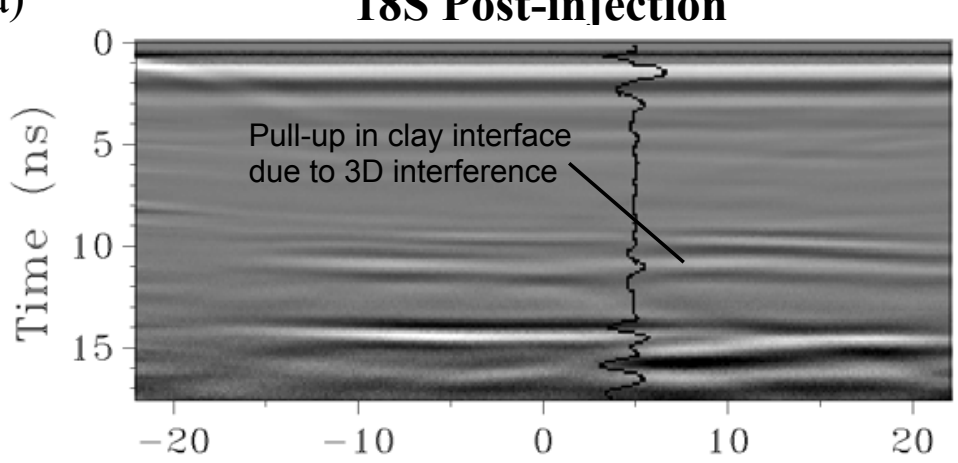

b)

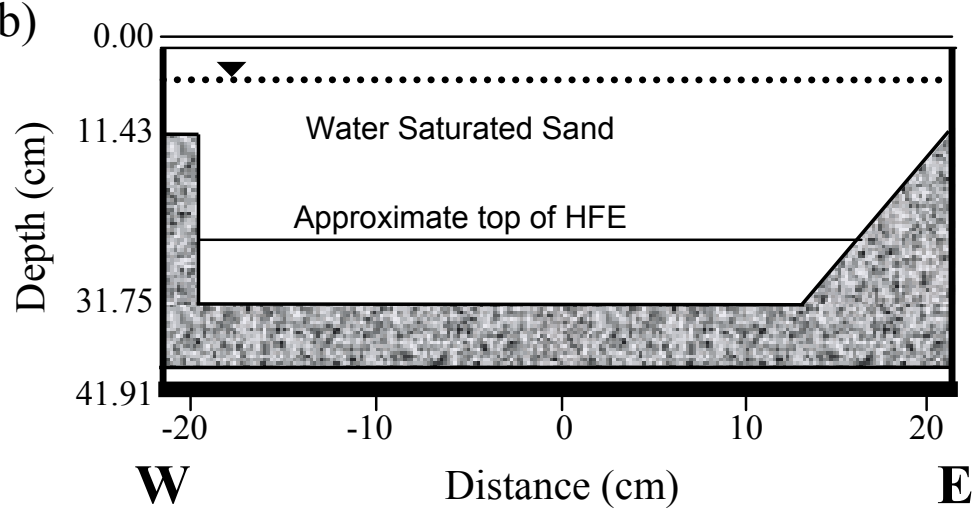

c)

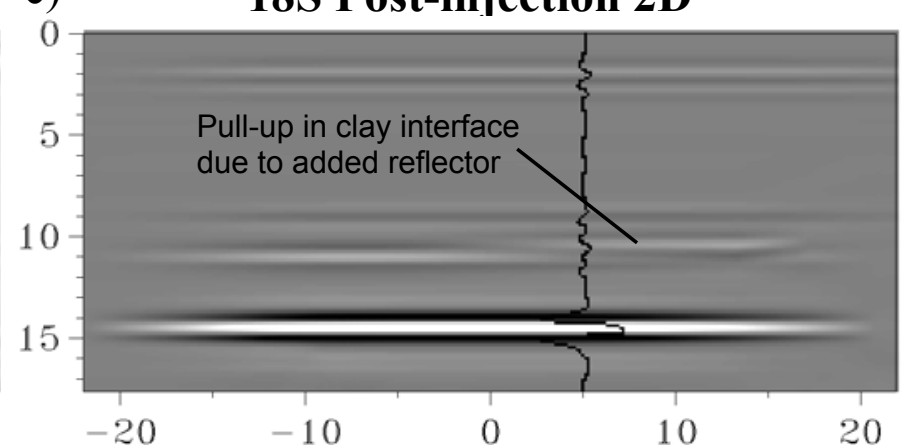

d)

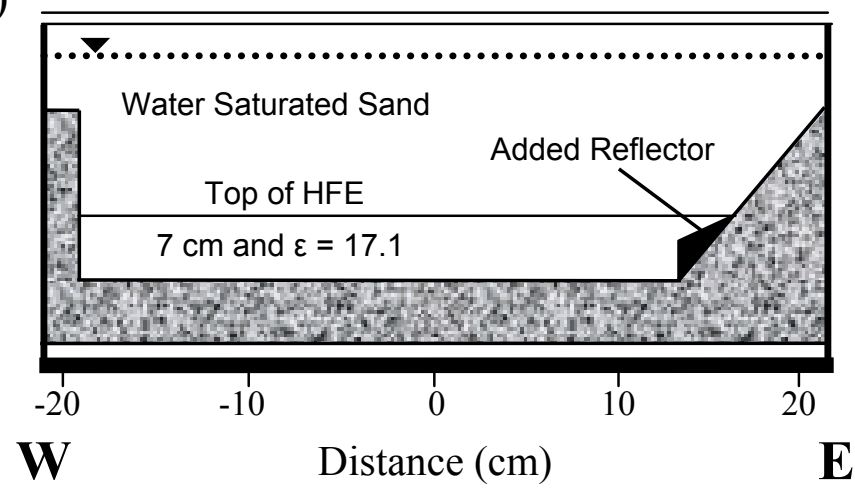

Figure 26: GPR images along $18 \mathrm{~S}$ at post-injection, looking north. Wiggle-trace displays are at $5 \mathrm{~cm}$ : a) GPR data; b) tank geometry; c) 2D model; and d) 2D model geometry. 
others, 2002) and used for a multiphase flow model calibration in Johnson and Poeter (2003a) are likely due to 2D interferences within a channel that are not accounted for in the 1D GPR modeling.

For a field setting where a DNAPL injection has already occurred, the identification or careful emplacement of targets (i.e., steel rods, steel sheets, underground conduits, and geologic features) with a known depth can improve the GPR interpretation. Emplacement of targets should avoid mobilization of the DNAPL. A target placed in areas where DNAPL is not present can be used to obtain permittivity of the natural materials at the site. The DNAPL volume above a target can be calculated by calibrating a 1D GPR model to the depth of the known feature. Flat lying targets are ideal, but other target configurations could also be used if their position is known and multidimensional influences are appropriately modeled.

\section{Acknowledgements}

Funding for this research was provided by a variety of projects within the United States Geological Survey, Geologic Division, Crustal Imaging and Characterization and Mineral Resources Teams. The U. S. Silica Company provided the sand used for this research. Assistance from Mike Powers on the use of the ground penetrating radar equipment was much appreciated.

\section{References}

American Society of Testing and Materials, 2002, Standard test methods for AC loss characteristics and permittivity (dielectric constant) of solid electrical insulation: D 150-98, American Society of Testing and Materials, $19 \mathrm{p}$.

Brewster, M.L., Annan, A.P., Greenhouse, J.P., Kueper, B.H., Olhoeft, G.R., Redman, J.D. and Sander, K.A., 1995, Observed migration of a controlled DNAPL release by geophysical methods: Ground Water, v. 33, no. 6, p. 977-987.

Greenhouse, J., Brewster, M., Schneider, G., Redman, D., Annan, P., Olhoeft, G.,Lucius, J., Sander, K. and Mazzella, A., 1993, Geophysics and solvents-The Borden experiment: The Leading Edge, v. 12, no. 4, p. 261-267. 
Johnson, R.H. and Poeter, E.P., 2003a, Inverse multiphase flow simulation to evaluate conceptual models, estimate intrinsic permeabilities and identify bias in field data, for a field-scale DNAPL injection in Borden sand given time-lapse GPR, Chapter 3 in Johnson, R.H., Characterization of subsurface DNAPL movement with ground penetrating radar and inverse multiphase flow simulations, Golden, Colo., Colorado School of Mines, Ph.D. dissertation T-5771, p. 22-55.

Johnson, R. H. and Poeter, E. P., 2003b, Accuracy of the iterative use of the BruggemanHanai-Sen mixing model to determine the proportions of a mixture of water, air and sand, Chapter 2 in Johnson, R.H., Characterization of subsurface DNAPL movement with ground penetrating radar and inverse multiphase flow simulations: Golden, Colo., Colorado School of Mines, Ph.D. dissertation T-5771, p. $4-21$.

Lucius, J.E. and Powers, M.H., 1997, Multi-frequency GPR surveys, in Symposium on the Application of Geophysics to Environmental and Engineering Problems '97 Proceedings: Environmental and Engineering Geophysics Society, v. 1, p. 355364.

Olhoeft, G.R., 1998, GRORADAR TM_Acquisition, processing, modeling and display of dispersive ground penetrating radar data: version 03.99, available at http://g-p-r.com (accessed Aug. 1, 2003).

Powers, M.H., 1995, Dispersive ground penetrating radar modeling in 2D: Golden, Colo., Colorado School of Mines, Ph.D. dissertation T-4820, 198 p.

Powers, M.H., 1997, Modeling frequency-dependent GPR: The Leading Edge, v. 16, no. 11, p. $1657-1662$.

Powers, M.H. and Olhoeft, G.R., 1995, GPRMODV2-One-dimensional full waveform forward modeling of dispersive ground penetrating radar data, version 2.0: U. S. Geological Survey Open-File Report 95-58, 41 p. + floppy diskette.

Sneddon, K.W., Powers, M.H., Johnson, R.H., and Poeter, E.P., 2002, Modeling GPR data to interpret porosity and DNAPL saturations for calibration of a 3-D multiphase flow simulation: U. S. Geological Survey Open-File Report 02-451, $29 \mathrm{p}$. 